UNIVERSIDADE DE SÃO PAULO

FACULDADE DE MEDICINA DE RIBEIRÃO PRETO

BRUNO ADONA RIBEIRO

Perfil do egresso e avaliação do programa de residência médica em ortopedia e traumatologia do Hospital das Clínicas da Faculdade de Medicina de Ribeirão Preto da Universidade de São Paulo

Ribeirão Preto 
BRUNO ADONA RIBEIRO

\section{Perfil do egresso e avaliação do programa de residência médica em ortopedia e traumatologia do Hospital das Clínicas da Faculdade de Medicina de Ribeirão Preto da Universidade de São Paulo}

\section{Versão Original}

Dissertação apresentada à Faculdade de Medicina de Ribeirão Preto da Universidade de São Paulo para obtenção do título de Mestre em Ciências.

Programa: Mestrado Profissional em Medicina Área de concentração: Medicina

Orientador: Prof. Dr. Edgard Eduard Engel

Ribeirão Preto 
Autorizo a reprodução e divulgação total ou parcial deste trabalho, por qualquer meio convencional ou eletrônico, para fins de estudo e pesquisa, desde que citada a fonte.

FICHA CATALOGRÁFICA

Ribeiro, Bruno Adona

Perfil do egresso e avaliação do programa de residência médica em ortopedia e traumatologia do Hospital das Clínicas da Faculdade de Medicina de Ribeirão Preto da Universidade de São Paulo, 2021.

79 f. il.; $30 \mathrm{~cm}$

Dissertação de Mestrado apresentada à Faculdade de Medicina de Ribeirão Preto/USP. Programa: Mestrado Profissional em Medicina. Área de concentração: Medicina.

Orientador: Engel, Edgard Eduard

1. Residência médica. 2. Ortopedia e traumatologia. 3. Perfil do egresso. 4. Educação médica. 
Nome: RIBEIRO, Bruno Adona

Título: Perfil do egresso e avaliação do programa de residência médica em ortopedia e traumatologia do Hospital das Clínicas da Faculdade de Medicina de Ribeirão Preto da Universidade de São Paulo.

Dissertação apresentada à Faculdade de Medicina de Ribeirão Preto da Universidade de São Paulo para obtenção do título de Mestre em Ciências.

Programa: Mestrado Profissional em Medicina

Área de concentração: Medicina

Aprovado em:

Banca examinadora:

Prof. Dr.

Instituição

Julgamento

Prof. Dr.

Instituição

Julgamento

Prof. Dr.

Instituição

Julgamento 
Para Ana Clara. 
Agradeço minha esposa, Bianca, por todas as suas virtudes, mas principalmente pela paciência, pelo carinho e por acreditar no que está por vir.

"O coração de uma mulher deve ser tão próximo de Deus que um homem precisa persegui-Lo para encontrá-la."

C. S. Lewis

Agradeço aos meus pais e irmãos pela confiança e pelo afeto.

Agradeço aos meus amigos, antigos e recentes, de perto e de longe.

Agradeço ao meu orientador, Prof. Dr. Edgard Eduard Engel, aos meus preceptores e aos meus colegas de profissão do HC-FMRP-USP, pela amizade conquistada, e pelo crescimento profissional e pessoal durante nossa convivência.

O presente trabalho foi realizado com apoio da Coordenação de Aperfeiçoamento de Pessoal de Nível Superior - Brasil (CAPES) - Código de Financiamento 001 
"Você não entende, Winston, que o indivíduo é apenas uma célula?

(George Orwell) 


\section{RESUMO}

RIBEIRO, Bruno Adona. Perfil do egresso e avaliação do programa de residência médica em ortopedia e traumatologia do Hospital das Clínicas da Faculdade de Medicina de Ribeirão Preto da Universidade de São Paulo. 2021. 79 f. Dissertação (Mestrado Profissional em Medicina) - Faculdade de Medicina de Ribeirão Preto, Universidade de São Paulo, Ribeirão Preto, 2021.

Estudo observacional, transversal e descritivo que buscou caracterizar o perfil dos egressos do Programa de Residência Médica em Ortopedia e Traumatologia (PRMOT) do Hospital das Clínicas da Faculdade de Medicina de Ribeirão Preto da Universidade de São Paulo (HC-FMRP-USP) e coletar dados sobre características do programa de ensino para orientar ações de aperfeiçoamento. A população do estudo foi constituída por 418 indivíduos que finalizaram suas atividades entre 1964 e 2020 e inclui os médicos egressos do PRMOT do HC-FMRP-USP, bem como aqueles que concluíram os programas de complementação especializada e Residência Médica em Cirurgia da Mão, Membro Superior e Microcirurgia (RMCMMC) lotados no mesmo departamento. Os dados foram coletados através de um questionário eletrônico. Foram localizados 302 egressos (73,6\% da população do estudo) e recebemos 214 respostas que correspondem a $70,8 \%$ dos contatos atingidos ou $52,2 \%$ do total de egressos. A análise dos dados foi baseada nessas respostas. A maioria da amostra é constituída por homens,198 (92,5\%), que moram no estado de São Paulo, 154 $(71,9 \%)$. Fizeram algum tipo de complementação especializada ou nova residência médica na área $184(86 \%)$ entrevistados. As duas subespecialidades mais prevalentes foram Cirurgia do Joelho, 63 (34,2\%) e Cirurgia da Mão, 49 (26,6\%). A pós-graduação fez parte da formação acadêmica de 87 pessoas $(40,6 \%)$, o trabalho com pesquisa é realizado por 79 egressos (36,9\%), majoritariamente em universidades públicas (81\%) e 130 (60,7\%) já haviam trabalhado com ensino médico, seja como preceptor ou docente, tanto para a graduação quanto para a residência médica. Notamos que a maioria, $152(71 \%)$, realmente atua com a respectiva subespecialidade, mas grande parte dos egressos trabalha também com traumatologia $(34,1 \%)$ e ortopedia geral $(31,8 \%)$. Na avaliação do sistema de ensino do programa e do grau de satisfação profissional os aspectos que se destacaram pela 
boa avaliação entre os entrevistados foram: o número de atendimentos e variabilidade dos casos, capacitação para atendimento em nível terciário e secundário e o preparo para o mercado de trabalho. A remuneração mensal, a carga horária de aulas teóricas e de realização de procedimentos cirúrgicos foi considerada insuficiente, sendo esses aspectos os com pior avaliação nas respostas objetivas e subjetivas. É possível afirmar que o estudo conseguiu traçar o perfil do egresso, determinou os principais pontos fortes do PRMOT do HC-FMRP-USP e ainda trouxe alertas para pontos que foram alvos de críticas.

Palavras-chave: Residência médica. Ortopedia. Traumatologia. Educação médica. 


\begin{abstract}
RIBEIRO, Bruno Adona. Graduate profile and evaluation of the medical residency program in orthopedics and traumatology at Hospital das Clínicas, Ribeirão Preto Medical School, University of São Paulo. 2021. 79 f. Dissertação (Mestrado Profissional em Medicina) - Faculdade de Medicina de Ribeirão Preto, Universidade de São Paulo, Ribeirão Preto, 2021.
\end{abstract}

Observational, cross-sectional and descriptive study that sought to characterize the profile of the graduates of the medical residency program in Orthopedics and Traumatology (MRPOT) at the Clinic Hospital of the Faculty of Medicine of Ribeirão Preto, University of São Paulo, and collect data on the characteristics of the teaching program to guide improvement actions. The study population consisted of 418 individuals who completed their activities between 1964 and 2020 and includes doctors who graduated from the MRPOT, as well as those who completed the specialized complementation programs and medical residency in hand surgery, all located in the same department. The data were collected through an electronic questionnaire. 302 graduates were found ( $73.6 \%$ of the study population) and we received 214 responses that correspond to $70,8 \%$ of the contacts reached or $52.2 \%$ of the total graduates. Most of the sample consists of men, 198 (92.5\%), who live in the state of São Paulo, 154 (71.9\%). 184 (86\%) underwent some type of specialized complementation or new medical residency in the area, and the two most prevalent subspecialties are Knee Surgery, 63 (34.2\%) and Hand Surgery, 49 (26.6\%). Post-graduation was part of the academic training of 87 people $(40.6 \%)$, the research work is mainly carried out in public universities (81\%) by 79 graduates (36.9\%) and 130 (60.7\%) had already worked with medical education either as a preceptor or professor for both undergraduate and medical residency. The majority, $152(71 \%)$, work with the respective subspecialty but most of the graduates also work with traumatology $(34.1 \%)$ and general orthopedics (31.8\%). In the evaluation of the program's educational system and the degree of professional satisfaction, the aspects that stood out for the good evaluation among the interviewees were: the number and variability of cases, training for care at the tertiary and secondary level and preparation for the job market. The monthly remuneration and the workload of theoretical classes and surgical 
procedures was considered insufficient, with these aspects being the worst evaluated in the objective and subjective responses. It is possible to state that the study was able to trace the profile of the graduates and determine the main strengths of the MRPOT, it also brings attention to the points that were the target of criticism.

Keywords: Medical residency. Orthopedics. Traumatology. Medical education. 


\section{LISTA DE GRÁFICOS}

Gráfico 1 - Distribuição dos egressos de acordo a década do ano de conclusão ....32

Gráfico 2 - Distribuição dos egressos por área de subespecialização.

Gráfico 3 - Distribuição dos egressos de acordo com a instituição onde fez a

subespecialização e o tempo de formado.

Gráfico 4 - Distribuição dos egressos por área de subespecialização de acordo com

o tempo de formado. .35

Gráfico 5 - Distribuição dos egressos que fizeram pós-graduação.

Gráfico 6 - Porcentagem da carga horária de trabalho utilizada com a primeira subespecialização

Gráfico 7 - Porcentagem da carga horária de trabalho utilizada com as demais subespecializações

Gráfico 8 - Total de horas semanais trabalhadas em hospitais ou serviços

financiados pelo SUS.

Gráfico 9 - Média do total de horas semanais trabalhadas (barra) e a proporção do total de horas trabalhadas na semana apenas no SUS (linha) de acordo com o tempo de formação

Gráfico 10 - Total de horas semanais trabalhadas em hospitais ou consultórios privados

Gráfico 11 - Média do total de horas semanais trabalhadas (barra) e a proporção do total de horas trabalhadas na semana apenas no sistema privado (linha) de acordo com o tempo de formação.

Gráfico 12 - Distribuição dos egressos conforme o salário mensal total. .39

Gráfico 13 - Remuneração mensal média (em $R \$$ ) de acordo com o tempo de formado.

Gráfico 14 - Remuneração mensal média de acordo com o local onde vive atualmente. 40

Gráfico 15 - Distribuição dos egressos de acordo com a porcentagem do salário mensal total que advém de trabalho em hospitais ou serviços financiados pelo SUS.

Gráfico 16 - Distribuição dos egressos de acordo com a porcentagem do salário mensal total que advém de trabalho em consultórios ou hospitais particulares. 
Gráfico 17 - Distribuição dos egressos de acordo com a porcentagem do salário mensal total que advém de trabalho com convênios médicos.

Gráfico 18 - Distribuição dos egressos de acordo com a porcentagem do salário mensal total que advém de trabalho com ensino ou formação médica.

Gráfico 19 - Distribuição dos egressos de acordo com a porcentagem do salário mensal total que advém de fontes de renda não relacionadas a ortopedia

Gráfico 20 - Distribuição dos egressos em atividades remuneradas que não dependem da formação como médico ortopedista .42

Gráfico 21 - Total de horas semanais trabalhadas em atividades remuneradas não relacionadas à ortopedia

Gráfico 22 - Total de horas semanais trabalhadas em atividades remuneradas não relacionadas à ortopedia

Gráfico 23 - Remuneração mensal média por especialidade e satisfação média com a remuneração e com a profissão 45 


\section{LISTA DE MAPAS}

Mapa 1 - Origem dos egressos sobre o território brasileiro ……..............................33

Mapa 2 - Distribuição dos egressos sobre o território brasileiro atualmente .............33 


\section{LISTA DE TABELAS}

Tabela 1- Distribuição dos egressos de acordo com a área de atuação profissional .37

Tabela 2- Análise das respostas às perguntas que utilizaram escala tipo Likert......43 Tabela 3- Médias e desvios padrão das respostas de acordo com a década em que foi finalizado o programa de residência.....................................................................4

Tabela 4- PRM que o egresso teria escolhido hoje ............................................. 46

Tabela 5- Subespecialização que o egresso teria escolhido hoje ............................46

Tabela 6 - Sugestões mais prevalentes para melhoria do PRMOT ..........................47 


\section{LISTA DE FIGURAS}

Figura 1 - Fluxograma de respostas recebidas .30 


\section{LISTA SIGLAS}

$\begin{array}{ll}\text { CNRM } & \text { Comissão Nacional de Residência Médica } \\ \text { CE } & \text { Complementação especializada } \\ \text { FMRP } & \text { Faculdade de Medicina de Ribeirão Preto } \\ \text { EUA } & \text { Estados Unidos da América } \\ \text { HC } & \text { Hospital das Clínicas } \\ \text { PRMOT } & \text { Programa de Residência Médica em Ortopedia e Traumatologia } \\ \text { SBCM } & \text { Sociedade Brasileira de Cirurgia da Mão } \\ \text { SUS } & \text { Sistema Único de Saúde } \\ \text { USP } & \text { Universidade de São Paulo } \\ \text { TCLE } & \text { Termo de Consentimento Livre e Esclarecido }\end{array}$




\section{LISTA DE SÍMBOLOS}

$\%$

$\pm$

(B) porcentagem

mais ou menos

marca registrada 
1. INTRODUÇÃO

2. OBJETIVOS

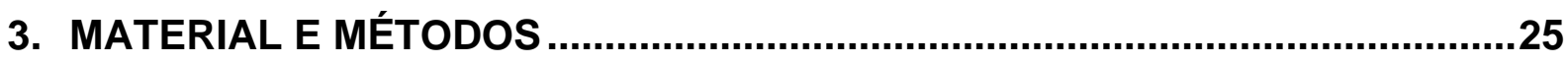

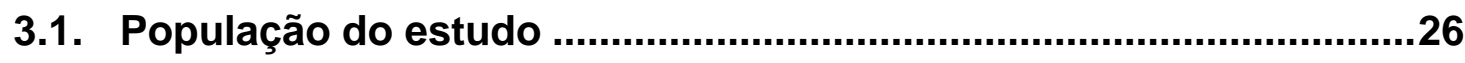

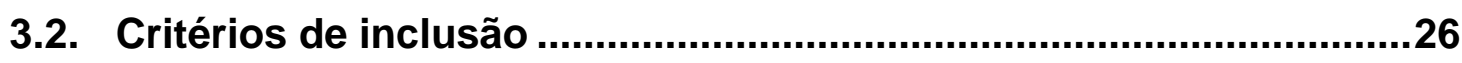

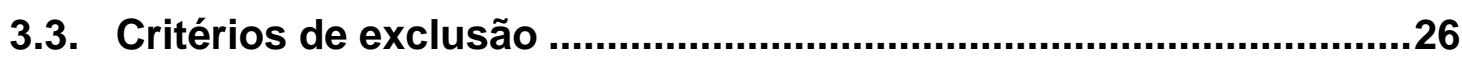

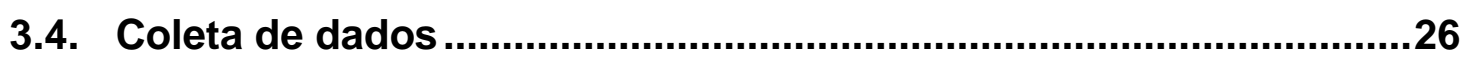

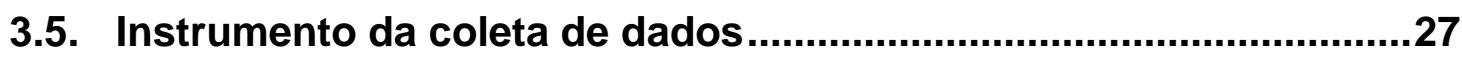

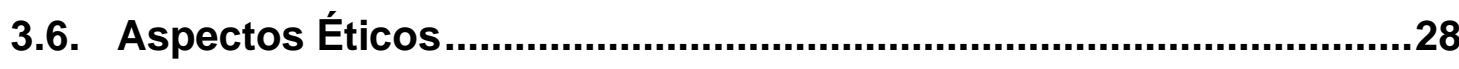

4. RESULTADOS E DISCUSSÃO

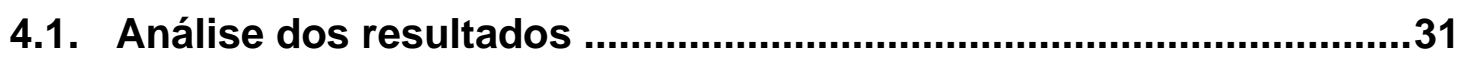

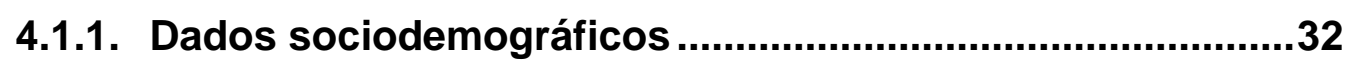

4.1.2. Formação acadêmica e profissional ...................................33

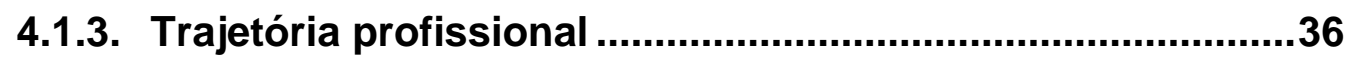

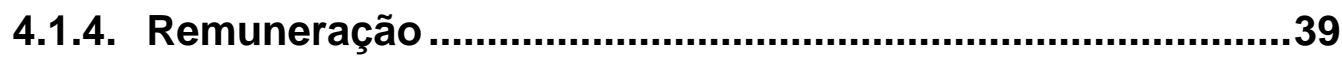

4.1.5. Avaliação do sistema de ensino da residência médica e grau de satisfação profissional..........................................................43

5. CONCLUSÃO

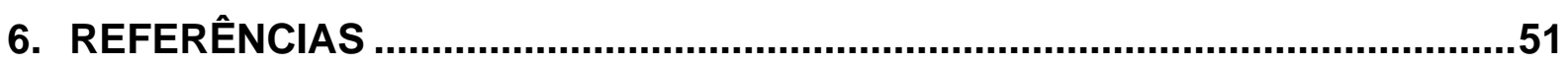

7. APÊNDICES

APÊNDICE A - TERMO DE CONSENTIMENTO LIVRE E ESCLARECIDO .59

APÊNDICE B - CONVITE PARA PARTICIPAÇÃO: ..................................62

APÊNDICE C - QUESTIONÁRIO.........................................................63 
INTRODUÇÃO 


\section{INTRODUÇÃO}

A residência médica é a forma internacionalmente aceita e considerada o padrão ouro para a especialização médica. É caracterizada pelo treinamento em serviço sob supervisão de profissionais qualificados. ${ }^{1}$ Para a concretização de bons Programas de Residência Médica (PRM), deve-se investir na melhoria e estruturação dos serviços da rede de saúde; na organização de apoio; na capacitação e remuneração de preceptores, supervisores de PRM e coordenadores das Comissões de Residência Médica; entre outros fatores. ${ }^{2-3}$

A qualidade de um programa de educação profissional pode, dentre outras formas, ser avaliada pelo perfil do profissional formado. Entretanto, o acompanhamento regular e sistemático de egressos é uma prática incomum em diversas áreas, especialmente entre instituições formadoras de profissionais da saúde. ${ }^{4-5}$ Existem poucos dados e publicações científicas abordando o perfil dos egressos de programas de especialização, tanto no Brasil quanto na literatura internacional.

O estudo da trajetória profissional dos egressos funciona como parte fundamental da autoavaliação das instituições de ensino e, se utilizado de forma correta, contribui para seu aperfeiçoamento. A análise do programa por parte dos egressos consegue informar elementos que devem ser mantidos ou expandidos $\mathrm{e}$ outros que requerem melhorias ou atenção. Além disso, tem a capacidade de criar ou reestabelecer conexões entre o egresso e a instituição, criando iniciativas educacionais, incentivando a pesquisa científica e oferecendo um importante crescimento tanto acadêmico quanto profissional aos envolvidos.

A criação de instrumentos e indicadores que proporcionem dados objetivos para uma avaliação completa acaba se tornando um grande desafio ${ }^{6-7}$. Nos estudos que envolvem educação médica normalmente são utilizados questionários que seguem normas visando principalmente objetividade analítica e altas taxas de resposta. ${ }^{8-12}$

Em abril de 1958 foi fundado o Departamento de Ortopedia da Faculdade de Medicina de Ribeirão Preto (FMRP). Por iniciativa do Professor José Paulo Marcondes de Souza foi criado o primeiro Programa de Residência Médica em Ortopedia e Traumatologia (PRMOT) do interior do Brasil que, em 1963, disponibilizava duas vagas anualmente. 
O PRMOT sempre foi uma das prioridades do Departamento e o seu fortalecimento consistiu, basicamente, em prover estrutura adequada de treinamento e atrair o maior número de candidatos oriundos dos diferentes estados do país ou de outros países da América Latina. Hoje disponibiliza doze vagas anualmente e se tornou o quinto maior programa do País. Há ainda mais um programa de residência médica no Departamento: a Cirurgia da Mão, Membro Superior e Microcirurgia, credenciada pela Sociedade Brasileira de Cirurgia da Mão (SBCM) e pela Comissão Nacional de Residência Médica (CNRM), que começou suas atividades em 1992 e recebe atualmente seis médicos para um programa de dois anos de duração. As demais subespecializações ou complementações especializadas (CE) recebem anualmente número variado de candidatos nas áreas de Ortopedia Pediátrica e pé, Cirurgia do Quadril, Cirurgia da Coluna, Cirurgia do Joelho e Trauma dos Membros Inferiores e Ortopedia Oncológica. ${ }^{13}$

A contínua avaliação da qualidade dos programas de formação médica e a busca pela excelência deve guiar seus coordenadores. Poucos parâmetros são capazes de avaliar fielmente os programas e, ao lado da análise do desempenho dos residentes em provas de título e da procura de candidatos pelo programa, a avaliação do perfil dos egressos aparece como um recurso pertinente. Este levantamento permitirá uma avaliação do PRMOT e poderá servir de material para implementação de mudanças ou manutenção de técnicas atualmente efetivas. 
OBJETIVOS 


\section{OBJETIVOS}

Caracterizar o perfil dos médicos egressos do Programa de Residência Médica em Ortopedia e Traumatologia do Hospital das Clínicas da Faculdade de Medicina de Ribeirão Preto da Universidade de São Paulo com dados sociodemográficos, formação acadêmica, trajetória profissional, remuneração e grau de satisfação com a profissão.

Avaliar o sistema de ensino do PRMOT sob o ponto de vista dos egressos, analisando suas virtudes e deficiências, a fim de compreender melhor a formação de especialistas em Ortopedia e Traumatologia e colaborar com os programas de residência nessa área. 
MATERIAL E MÉTODOS 


\section{MATERIAL E MÉTODOS}

Estudo observacional, transversal e descritivo.

Além da abordagem predominantemente quantitativa, apresenta informações subjetivas que somam à análise um aspecto qualitativo.

\subsection{População do estudo}

A população do estudo foi constituída pelos médicos egressos do PRMOT do HC-FMRP-USP e aqueles que concluíram os programas de complementação especializada e o PRM em Cirurgia da Mão lotados no Departamento de Ortopedia e Anestesiologia.

\subsection{Critérios de inclusão}

Foram incluídos 418 médicos egressos provenientes do PRMOT do HC-FMRPUSP, dos programas de complementação especializada ou do PRM em Cirurgia da Mão lotados no Departamento de Ortopedia e Anestesiologia, que finalizaram essas atividades entre 1964 e 2020 e que estavam incluídos na lista do Sistema de Informação da CNRM (SisCNRM) ou no banco de dados do HC-FMRP-USP.

\subsection{Critérios de exclusão}

Foram excluídos apenas os indivíduos que não concluíram o programa de residência ou que vieram a óbito antes do período da pesquisa.

\subsection{Coleta de dados}

Os dados foram coletados através de um questionário eletrônico enviado no período entre novembro de 2019 a dezembro de 2020.

A busca pelas informações de contato dos egressos se mostrou um dos grandes desafios da pesquisa. As informações iniciais foram obtidas do banco de dados disponível no SisCNRM e dos dados mantidos pelo Departamento de Ortopedia e Anestesiologia do HC-FMRP-USP. 
Vale destacar que as listas disponibilizadas pelos meios citados acima eram compostas basicamente pelo nome do egresso, sem outros detalhes como telefone, endereço de e-mail ou endereço postal.

Partimos de uma lista com 418 nomes, 74 endereços de e-mail e cerca de 40 números de telefone. Após o contato com esses primeiros indivíduos, somado às informações pessoais dos próprios pesquisadores, foram obtidos mais dados. Finalizamos a pesquisa com 105 endereços de e-mail e 255 números de telefone, o que nos fez atingir diretamente 302 pessoas.

$\mathrm{Na}$ tentativa de alcançar mais egressos e mais respostas lançamos mão de duas estratégias bem estabelecidas: (1) amostragem em bola de neve ou snowball sampling, solicitando aos entrevistados que nos enviassem contatos que possuíssem, ou (2) respondent-driven sampling, enviando o link do questionário em todos os convites (Apêndice B) solicitando o compartilhamento para aqueles egressos contidos em suas próprias listas de contatos. ${ }^{14-16}$

\subsection{Instrumento da coleta de dados}

O instrumento utilizado para a coleta dos dados foi um questionário (Apêndice C) composto majoritariamente por perguntas objetivas e por algumas perguntas abertas e subjetivas com caráter não obrigatório, que davam oportunidade aos entrevistados expandirem as respostas anteriores. Para criação e envio do questionário eletrônico foi utilizada a ferramenta Google Forms.

As perguntas foram divididas em 6 grupos: (1) dados sociodemográficos, (2) formação acadêmica e profissional, (3) avaliação do sistema de ensino do programa de residência médica, (4) trajetória profissional, (5) remuneração e (6) grau de satisfação com a profissão.

A elaboração do questionário e as táticas para melhorar a taxa de resposta dos egressos seguiram recomendações já consolidadas para este modelo de trabalho. ${ }^{6,7,17}$ Nos grupos de perguntas para avaliação do sistema de ensino do programa e do grau de satisfação com a profissão utilizou-se uma escala numérica do tipo Likert, de cinco pontos, para otimizar a confiabilidade e a velocidade de resposta de todo o questionário. ${ }^{18}$

Para obter as respostas, foram necessários diversos contatos através de e-mail ou até mesmo de redes sociais, sendo que essas se mostraram as maiores aliadas 
no aumento da taxa de resposta do questionário. A cada 3 meses foram enviados emails contendo o convite (Apêndice B). Outro mecanismo utilizado foram os aplicativos de mensagens para celulares. Através do contato telefônico foram criados grupos no qual os participantes eram distribuídos de acordo com a década em que fizeram parte do programa de residência. Era permitido e incentivado adicionar colegas contemporâneos aos grupos. O link para acesso ao questionário foi enviado duas vezes dessa forma, com um intervalo de 30 dias entre eles.

O Termo de Consentimento Livre e Esclarecido (TCLE) era apresentado no início do questionário e o seu aceite era requisito obrigatório para prosseguir. Através dele era garantido sigilo sobre as informações fornecidas (Apêndice $A$ ).

Previamente à coleta de dados foi realizado um teste piloto com 9 egressos que concluíram o PRMOT entre 1991 e 2019 para identificar problemas de interpretação e dificuldades metodológicas, o que possibilitou a adequação do questionário antes do início do estudo.

\subsection{Aspectos Éticos}

O projeto e o instrumento de pesquisa foram aprovados pelo Comitê de Ética em Pesquisa do HC-FMRP-USP sob o parecer 3.564 .512 e CAAE: 16677019.8.0000.5440 e estão de acordo com as diretrizes e normas regulamentadoras de pesquisas envolvendo seres humanos. ${ }^{19}$ 


\section{RESULTADOS E DISCUSSÃO}

Foram incluídos no estudo 418 egressos. Esses indivíduos finalizaram o programa de residência entre 1964 e 2020 e participaram do PRMOT, Residência Médica em Cirurgia da Mão ou complementações especializadas.

A amostra total é constituída por 390 homens (93,3\%) e 28 mulheres (6,7\%), resultado compatível com a distribuição entre sexos na população de médicos ortopedistas do Brasil, onde o total de mulheres corresponde a $6,5 \%$ do total de especialistas. ${ }^{20}$

Foram excluídos da amostra inicial 8 pessoas por óbito, resultando em uma amostra final de 410 indivíduos.

O questionário foi enviado para 302 egressos $(73,6 \%)$ e foram recebidas 214 respostas $(52,2 \%)$. Dentre eles 71 realizaram apenas a especialização em Ortopedia e Traumatologia, 130 fizeram o PRMOT e continuaram aqui para a subespecialidade e apenas 13 não eram egressos do PRMOT e vieram para o HC-FMRP-USP exclusivamente para complementação especializada (Figura 1).

Figura 1 - Fluxograma de respostas recebidas

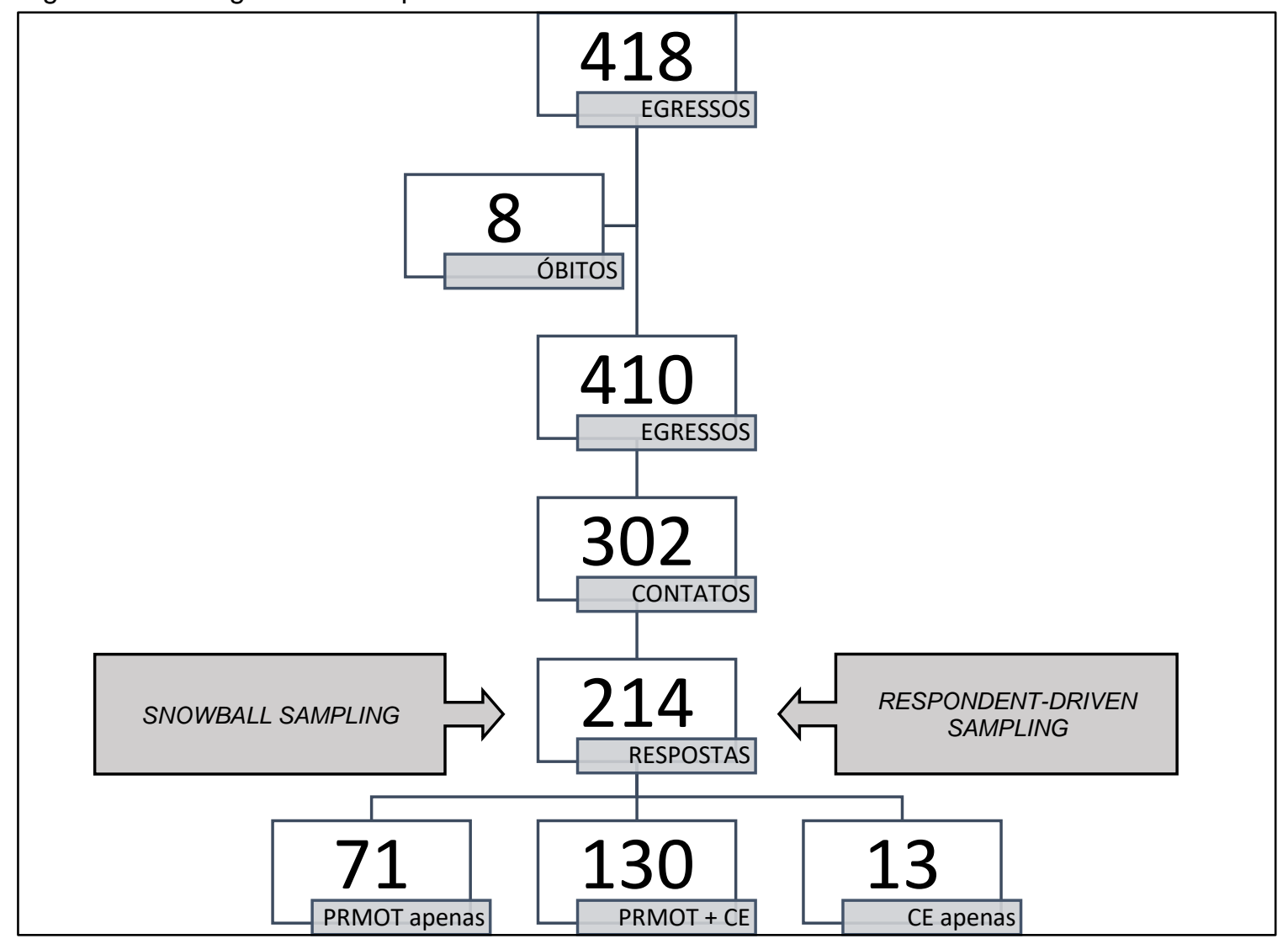


O número de respostas obtidas se mostrou semelhante ao encontrado em outros trabalhos brasileiros: egressos de programas de residência em Medicina de Família e Comunidade do estado de São Paulo, com 55,1\%;21 avaliação do PRM do Departamento de Pediatria da Faculdade de Medicina da USP, com 33,6\%; ${ }^{4}$ perfil de egressos de residência de Medicina de Família e Comunidade do Murialdo, com 51,6\%;22 perfil dos médicos e enfermeiros do Programa de Saúde da Família, com $58,5 \%$;3 e perfil dos egressos do curso de especialização em Saúde da Família do Espírito Santo, com $47 \%$ de resposta. ${ }^{24}$

A taxa de resposta baseada no número de pessoas que receberam o link do questionário não pôde ser calculada com precisão, uma vez que utilizamos de estratégias (snowball sampling e respondent-driven sampling) que não permitiram ter o controle de todos os egressos alcançados.

$\mathrm{Na}$ literatura internacional a média da taxa de resposta para pesquisas realizadas através de questionários são próximas de 60\%. Uma revisão sistemática portuguesa recente demonstrou $56 \%$ de resposta média, apesar de considerar ser um dado variável e bastante heterogêneo entre os estudos. ${ }^{25}$

Com o uso ampliado de ferramentas eletrônicas e auxílio das redes sociais temse exigido taxas de resposta cada vez mais altas para publicação de um trabalho que inclui pesquisa através de questionários, atualmente algumas revistas exigem e aceitam apenas taxas de resposta próximas de $80 \%{ }^{26}$

\subsection{Análise dos resultados}

A análise dos dados foi realizada com as respostas de 214 egressos. Para facilitar a compreensão será subdividida pelos grupos de perguntas citados anteriormente.

Nas perguntas para avaliação do sistema de ensino do programa de residência médica e do grau de satisfação com a profissão foram utilizadas, como opção de resposta, uma escala numérica do tipo Likert de 5 pontos, onde o número 1 correspondia a "nada satisfeito" e o número 5 a "muito satisfeito" (Apêndice $C$ ). A confiabilidade do questionário nestas questões apresentou um coeficiente alfa de Cronbach de 0,762, considerado substancial. ${ }^{27}$ Através do software SPSS (Statistical Package Social Science) versão 20.0 foi aplicado o teste de esfericidade de Bartlett, que se demonstrou significativo $(p<0,0005)$, e foi encontrada uma medida de Kaiser- 
Meyer-Olkin satisfatória de 0,787 , ambas as técnicas são utilizadas para confirmar a medida de adequação da amostra (Measuring of Sampling Adequacy - MSA). ${ }^{28}$

Para as análises descritivas e quantitativas utilizamos médias associadas a desvio padrão e porcentagens.

\subsubsection{Dados sociodemográficos}

A maioria da amostra é constituída por homens, 198 (92,5\%). Mulheres foram responsáveis por 16 respostas $(7,5 \%)$. $\mathrm{O}$ ano de conclusão dos que responderam variou de 1972 a 2020 e no gráfico 1 estão distribuídos por décadas.

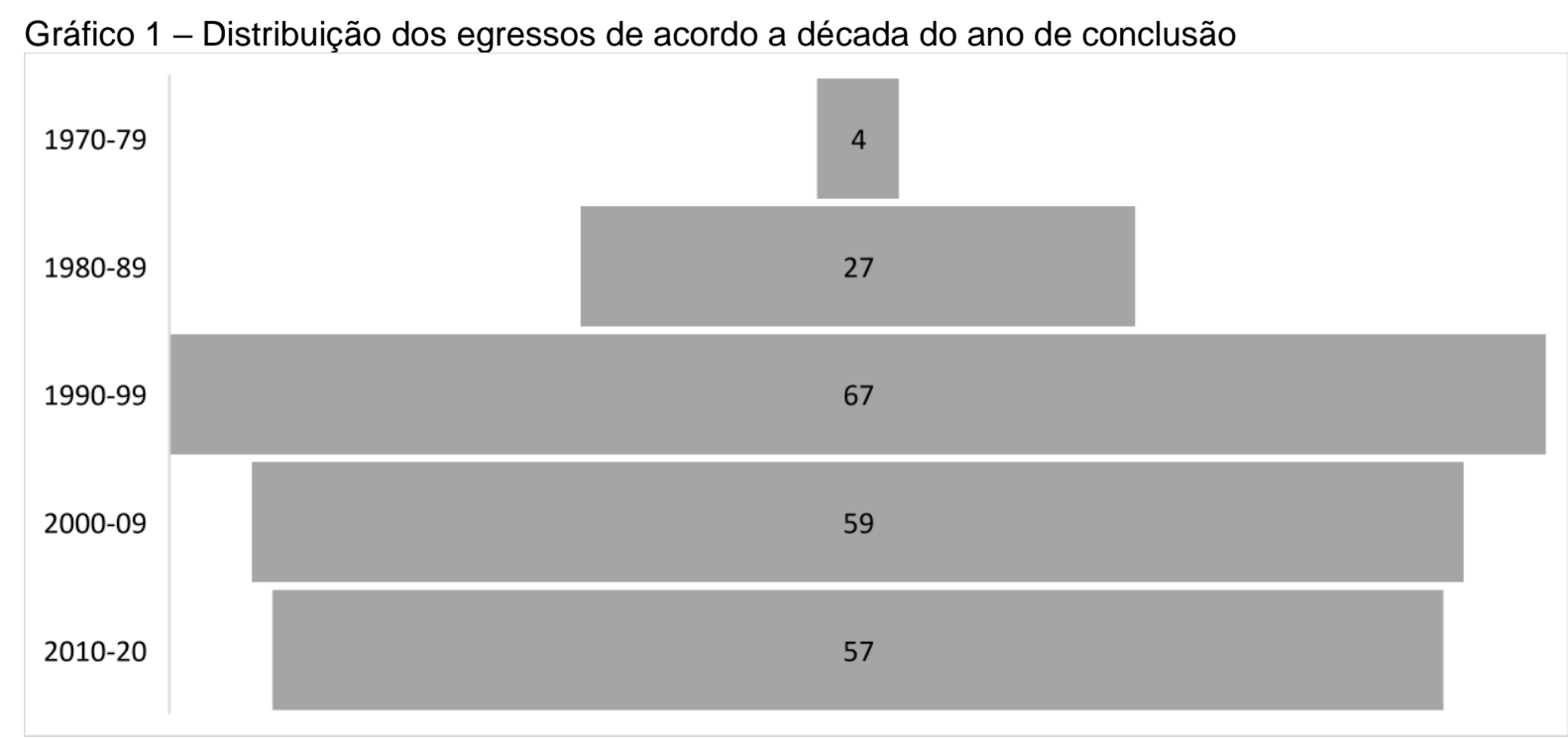

Com o auxílio dos mapas abaixo, notou-se uma tendência à descentralização dos egressos. Em São Paulo, por exemplo, houve um decréscimo de $16 \%$ em relação ao número de egressos originários do estado. A região Norte do país, conta hoje com 7 egressos sendo que nenhum havia declarado anteriormente ser originário da região.

Atualmente, 154 indivíduos moram em São Paulo $(71,9 \%)$ e 65 continuaram vivendo em Ribeirão Preto. Em relação aos demais estados, 13 vivem em Minas Gerais $(6,1 \%), 5$ na Bahia (2,1\%), 5 no Ceará $(2,1 \%)$ e outros 13 em outros estados. Essa distribuição é encontrada no Mapa 2. Cinco egressos responderam que atualmente moram fora do país. 
Mapa 1 - Estado brasileiro de origem dos egressos

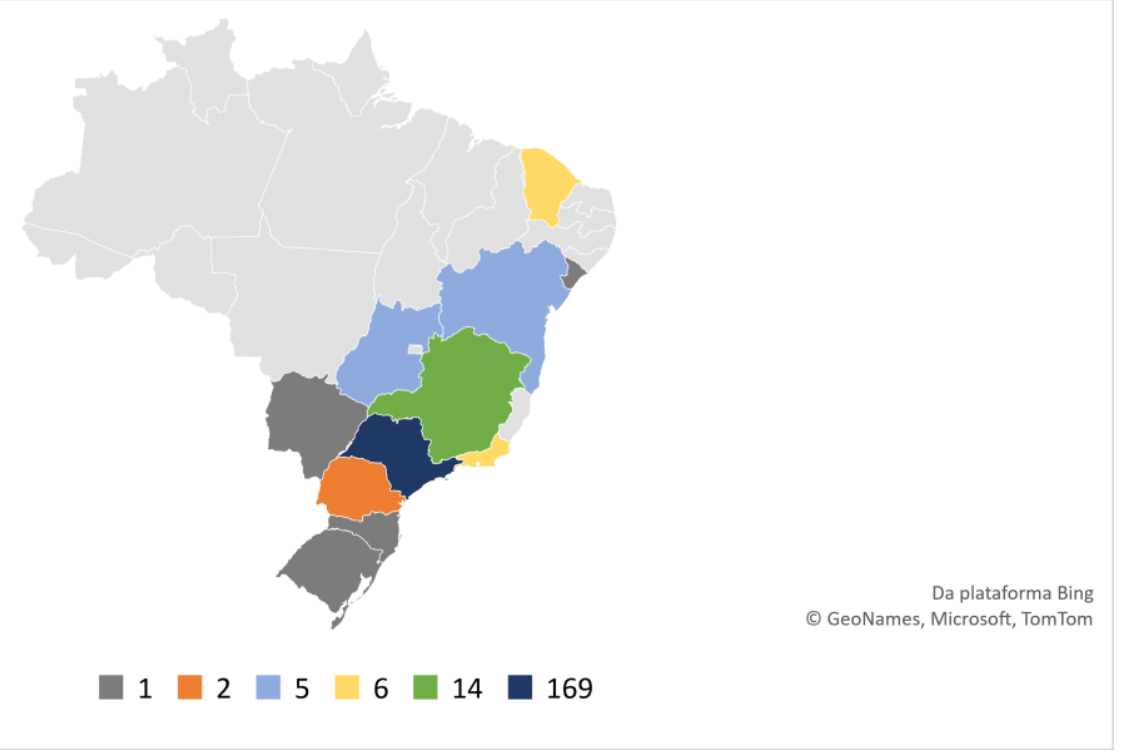

Mapa 2 - Distribuição dos egressos sobre o território brasileiro atualmente

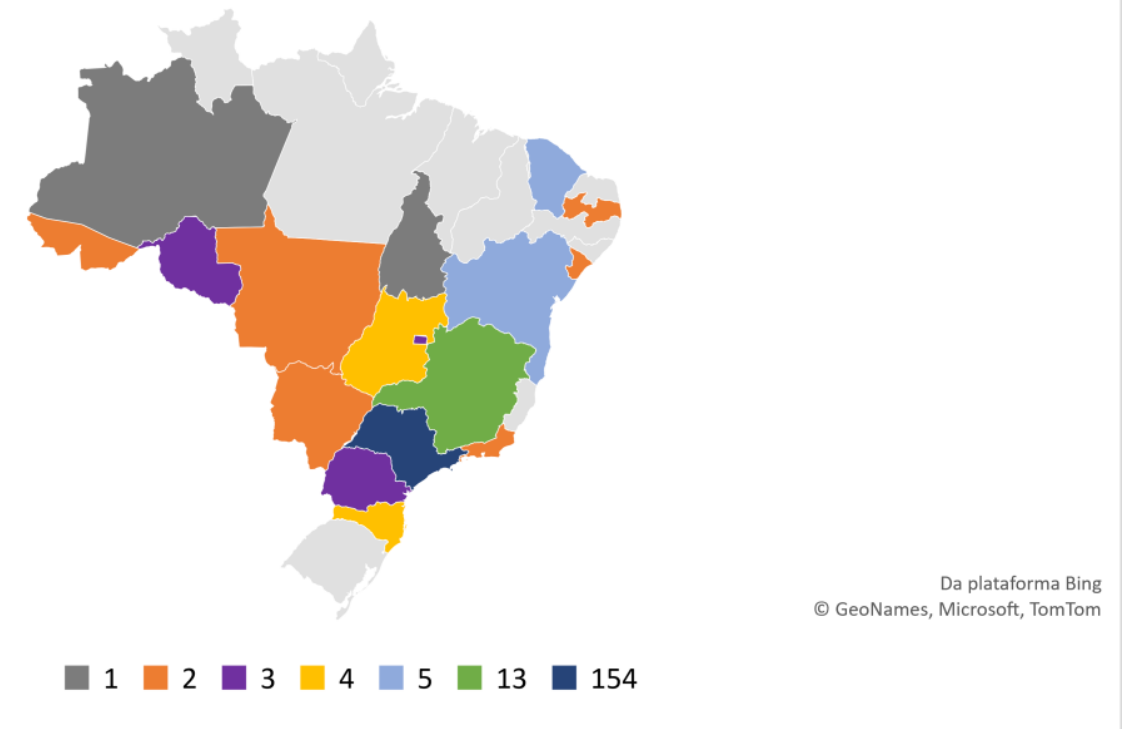

\subsubsection{Formação acadêmica e profissional}

Após a conclusão do PRMOT os médicos egressos tendem a não interromper a formação profissional, sendo que 184 (86\%) fizeram algum tipo de complementação especializada ou nova residência médica na área, 48 deles mais que uma.

O gráfico 2 traz informações sobre a distribuição dos ortopedistas de acordo com a subespecialização. A mais realizada foi Cirurgia do Joelho (e trauma) com 63 $(34,2 \%)$. A segunda foi Cirurgia da Mão com 49 (26,6\%). 
No HC-FMRP-USP o programa de complementação especializada em Cirurgia do Joelho inclui, excepcionalmente em relação a outros programas no Brasil, o trauma dos membros inferiores e por isso foi colocada uma observação entre parênteses no gráfico. O mesmo acontece com o programa de Ortopedia Pediátrica: no HC-FMRPUSP são incluídas ao programa as afecções do pé.

Gráfico 2 - Distribuição dos egressos por área de subespecialização.

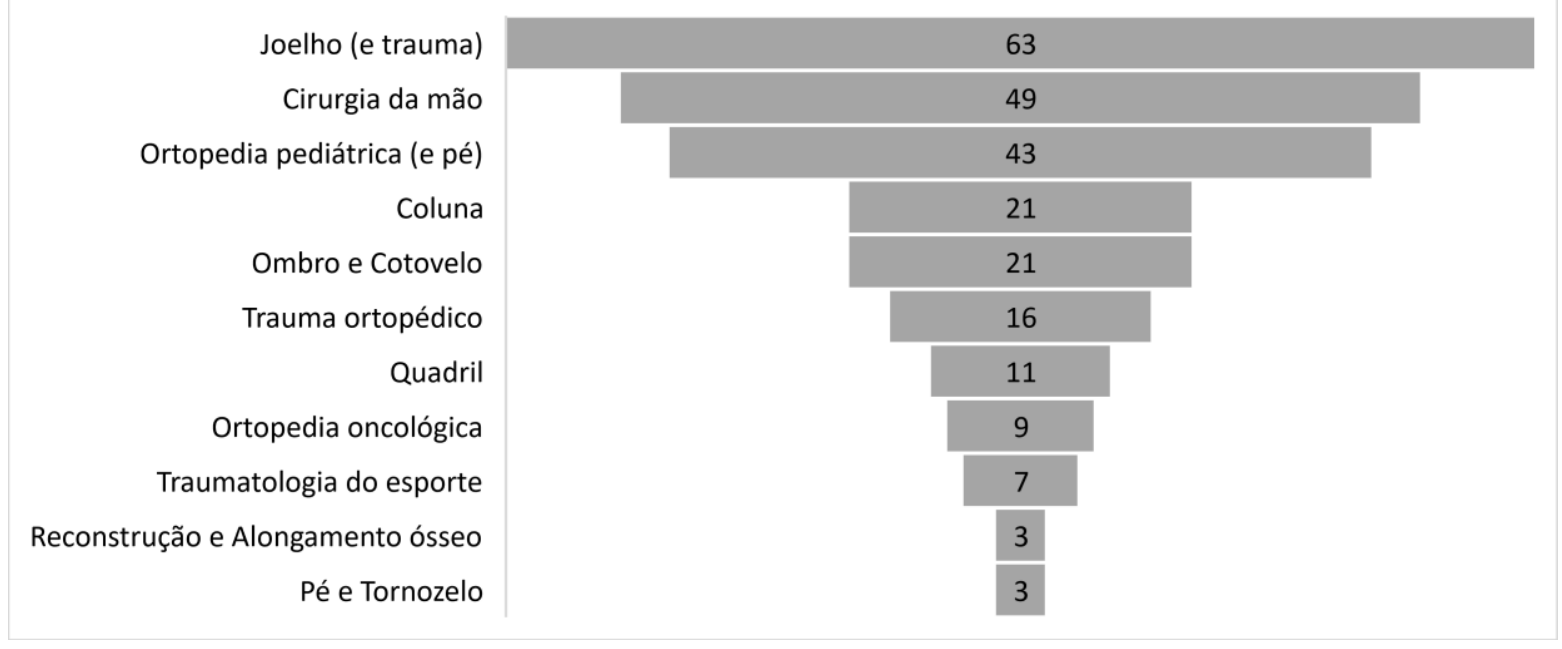

Na última década houve mudança no comportamento dos egressos em relação a instituição na qual foi realizada a subespecialização. O HC-FMRP-USP, responsável pela formação de quase todos os subespecialistas entre 2000 e 2009, manteve-se como principal instituição formadora, mas perdeu espaço para outras escolas, o que era mais frequente nos primeiros anos do programa (gráfico 3).

Gráfico 3 - Distribuição dos egressos de acordo com a instituição onde fez a subespecialização e o tempo de formado.

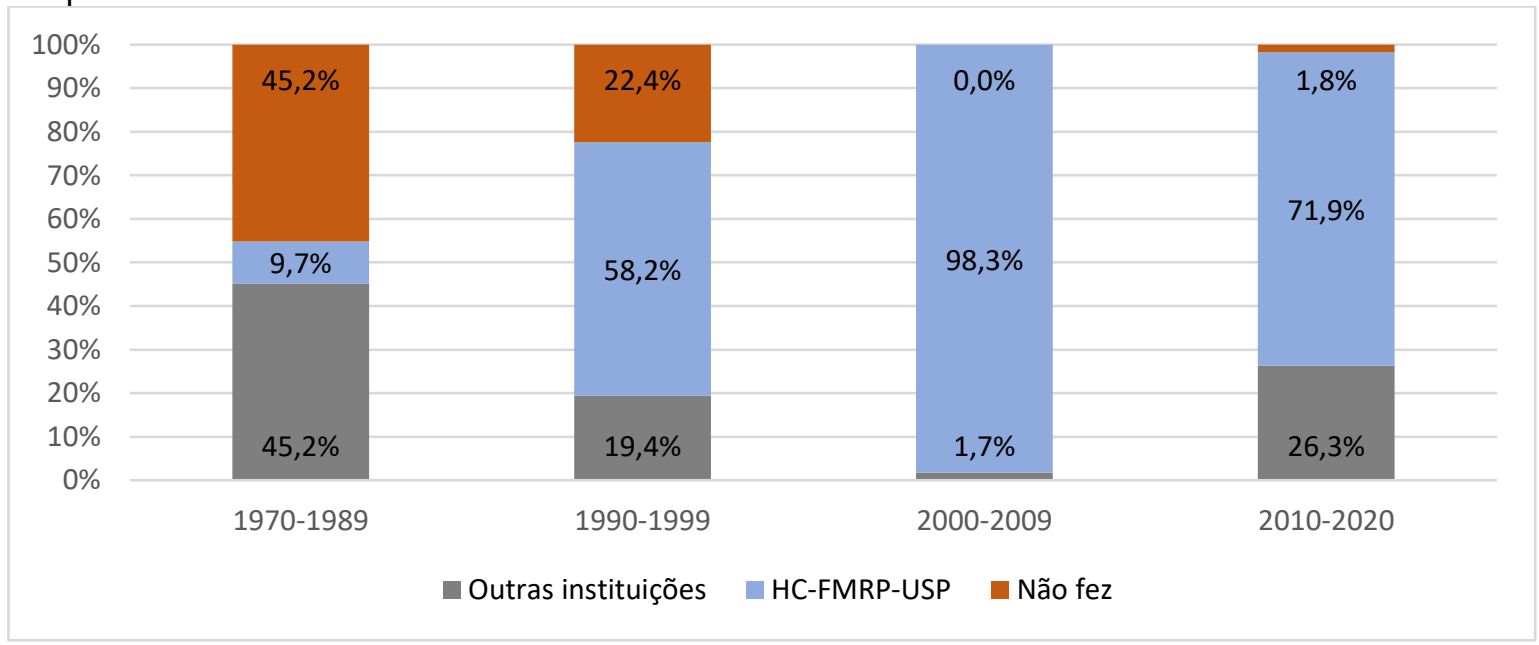


$\mathrm{Na}$ análise da distribuição de egressos nas subespecialidades de acordo com o tempo de formação (gráfico 4) nota-se que aqueles que não fizeram subespecialização encontram-se majoritariamente nas duas barras à esquerda e que as duas barras a direita são mais segmentadas, possuem mais cores. Isso significa que hoje em dia o foco na subespecialidade é mais expressivo. O número de subespecialistas é maior e o número de subespecialidades também.

Gráfico 4 - Distribuição dos egressos por área de subespecialização de acordo com o tempo de formado.

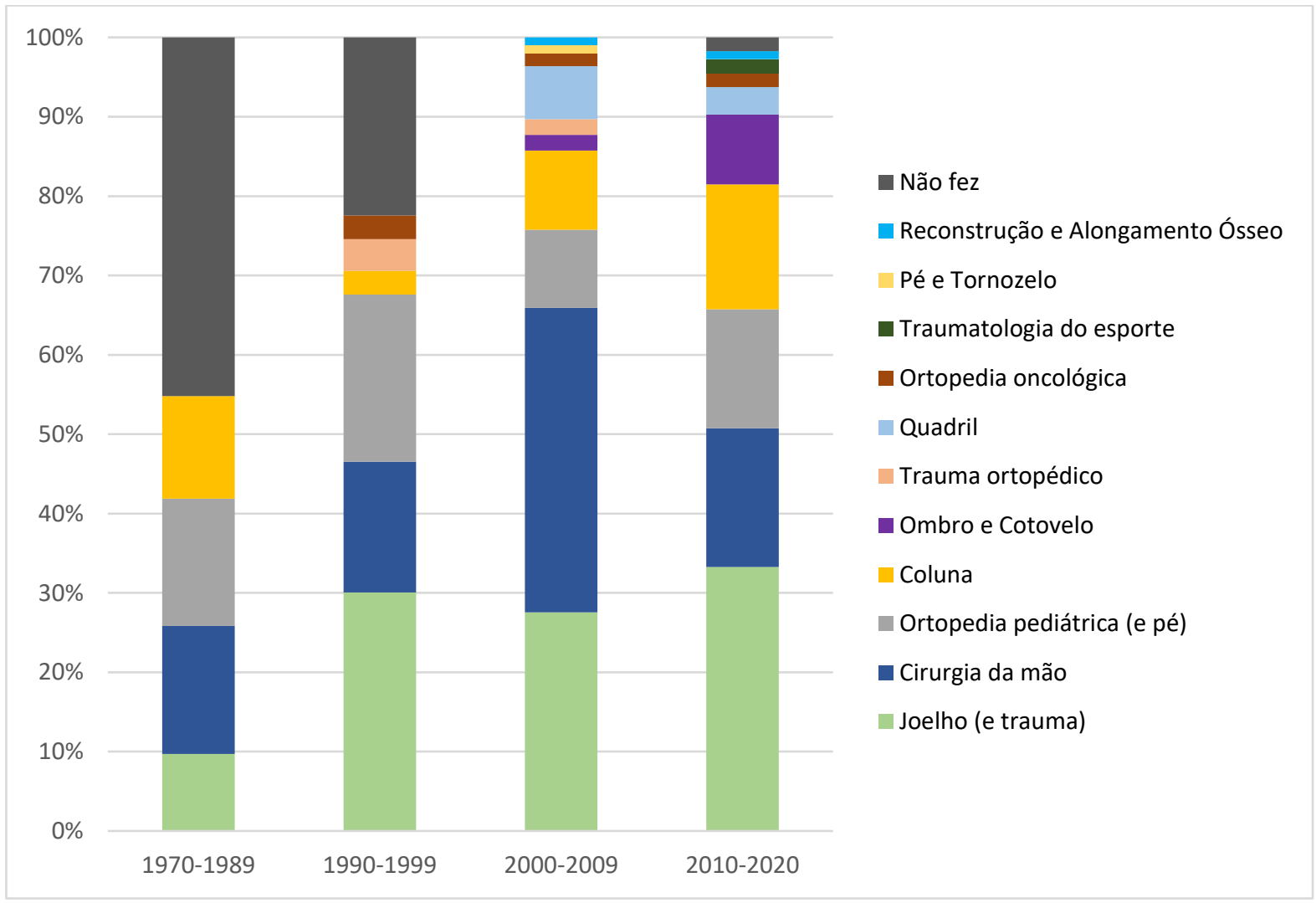

Outras especialidades médicas reconhecidas ${ }^{20}$ que não utilizam a Ortopedia como pré-requisito para sua realização também foram citadas pelos entrevistados, são elas: acupuntura, medicina legal e perícia médica, medicina do tráfego, medicina do trabalho e medicina esportiva.

Em relação à formação acadêmica, 87 entrevistados (40,6\%) fizeram algum tipo de pós-graduação, sendo que $66(30,8 \%)$ optaram pela realização do mestrado, 29 (13,6\%) pelo doutorado e 8 (3,7\%) pelo pós-doutorado (gráfico 5). É pertinente citar que 79 (36,9\%) egressos realizaram ou realizam pesquisa na área da saúde, 81\% em universidades públicas. 
Gráfico 5 - Distribuição dos egressos que fizeram pós-graduação.

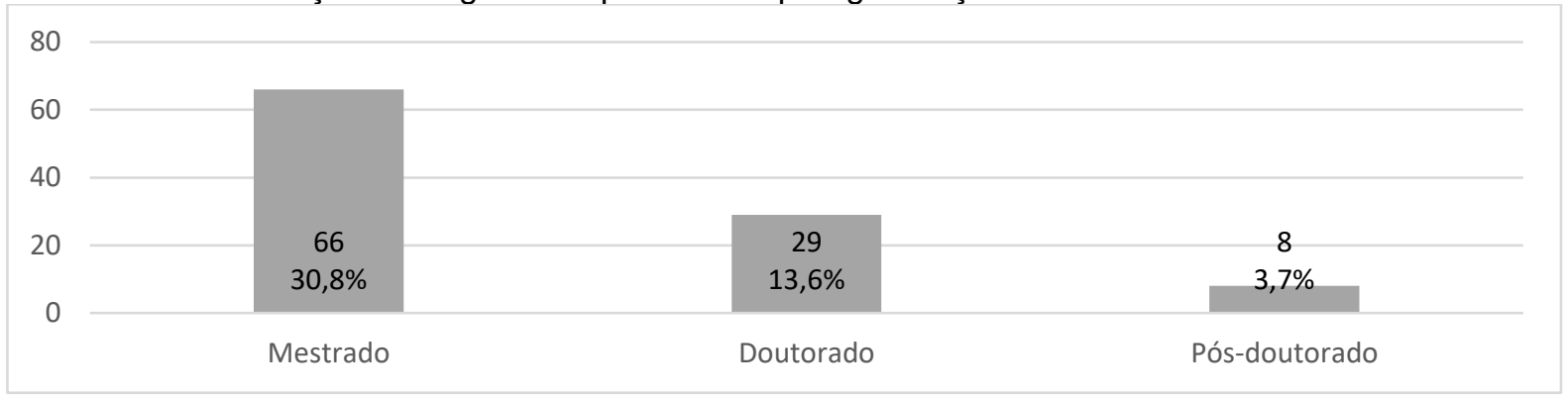

\subsubsection{Trajetória profissional}

O gráfico 6 mostra a relação entre a carga horária de trabalho (em porcentagem) que o médico egresso dedica à sua primeira subespecialização após o término do PRMOT. A maioria (56,7\%) dos médicos que possuem subespecialização utiliza mais de $80 \%$ do seu tempo de trabalho com ela. O gráfico 7 analisa a mesma variável, porém avalia o tempo dedicado à segunda subespecialidade para àqueles que optaram por fazer mais de uma.

Gráfico 6 - Porcentagem da carga horária de trabalho utilizada com a primeira subespecialização

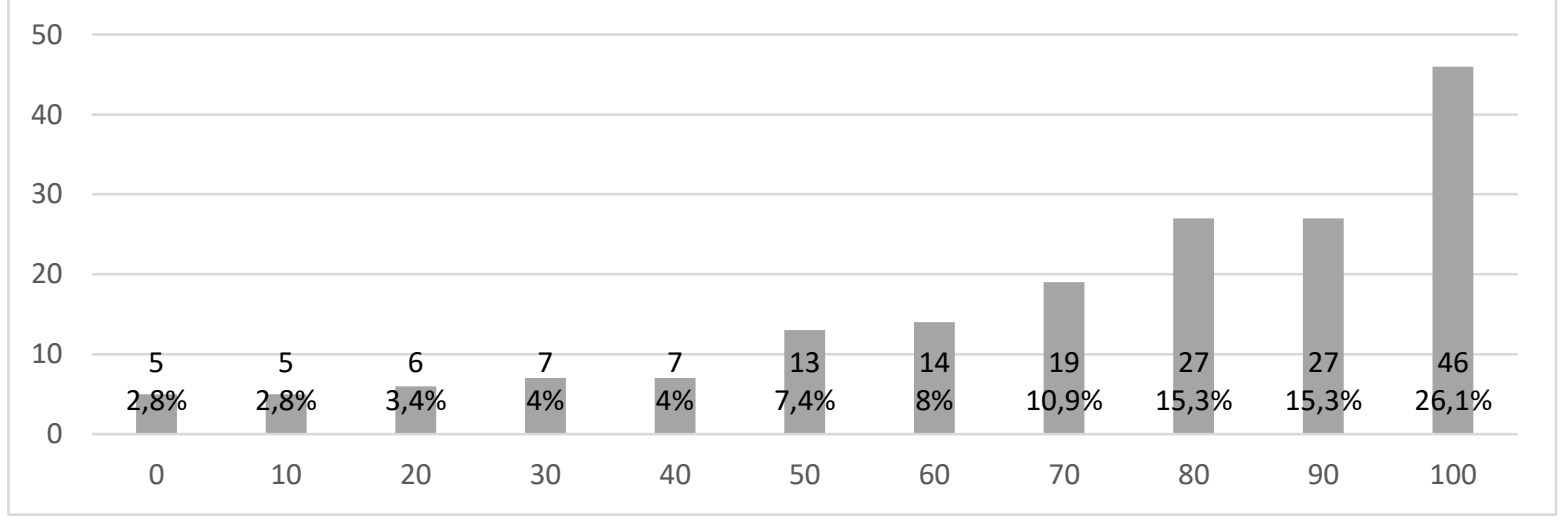

Gráfico 7 - Porcentagem da carga horária de trabalho utilizada com as demais subespecializações

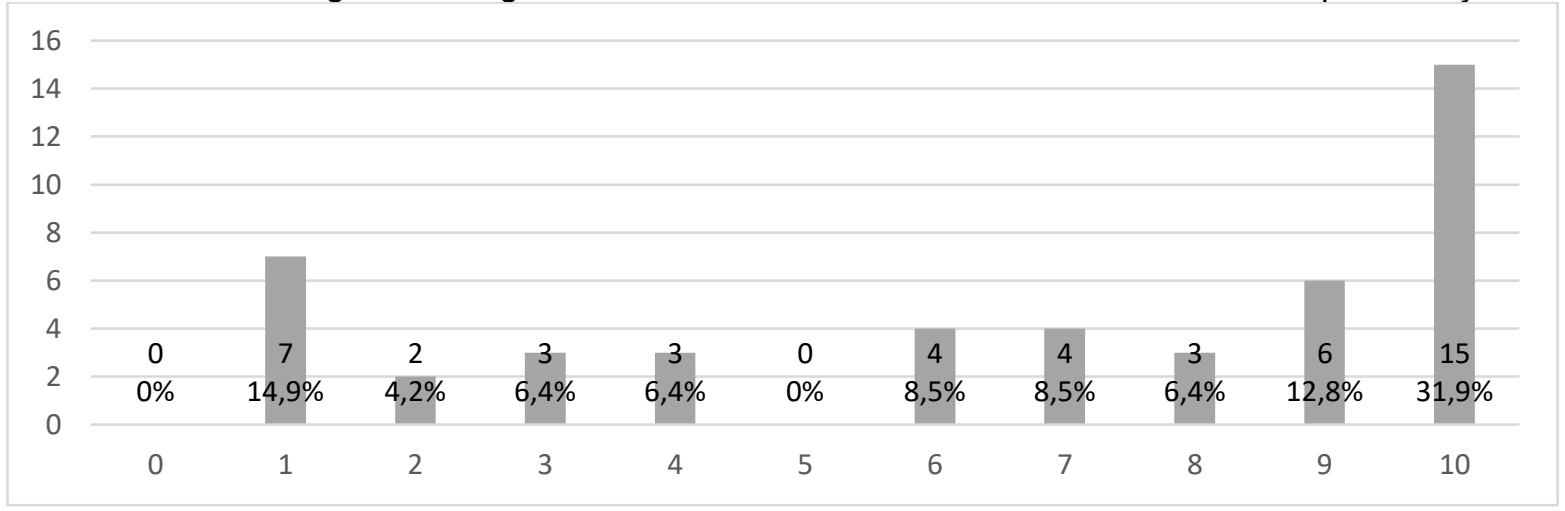


A área de atuação também fez parte do questionário e conseguimos avaliar como os entrevistados utilizavam na prática a formação acadêmica e profissional de maneira mais direta. Nessa pergunta era possível assinalar mais do que uma opção. Notamos que a maioria, 152 (71\%), utiliza as subespecialidades adquiridas no trabalho diário, e que grande parte dos entrevistados ainda utiliza seu tempo tanto com traumatologia quanto com ortopedia geral (Tabela 1).

Tabela 1- Distribuição dos egressos de acordo com a área de atuação profissional

\begin{tabular}{lll}
\hline Área de atuação & N & $\%$ \\
\hline Ortopedia subespecialidade & 152 & 71,0 \\
Traumatologia & 73 & 34,1 \\
Ortopedia Geral & 68 & 31,8 \\
Ensino / Pesquisa & 38 & 17,8 \\
Concluindo formação & 31 & 14,5 \\
Gerenciamento de clínicas / hospitais & 9 & 4,2 \\
Medicina legal & 7 & 3,3 \\
Dor & 5 & 2,3 \\
Medicina do trabalho & 5 & 2,3 \\
Acupuntura & 4 & 1,9 \\
Empresário & 2 & 0,9 \\
Terapia por ondas de choque & 1 & 0,5 \\
SAMU & 1 & 0,5 \\
Aposentado & 1 & 0,5 \\
Medicina do esporte & 1 & 0,5 \\
Gestão em saúde & 1 & 0,5 \\
Medicina de familia e comunidade & 1 & 0,5 \\
\hline
\end{tabular}

No ensino médico como área de atuação, notou-se que 130 (60,7\%) já haviam trabalhado na área, seja como preceptor ou docente para a graduação (78 indivíduos) ou para a residência médica (105 indivíduos). Os que trabalham ou já trabalharam como docentes somam 43 egressos, 32 desses em um programa de residência médica e 31 com a graduação em medicina. Números expressivos e que ajudam a caracterizar cada vez mais o perfil do serviço como um centro formador de profissionais para auxiliar o ensino médico no país.

Foi constatado que 148 pessoas $(69,1 \%)$ mantêm a atuação profissional no SUS e que apenas $11(5,1 \%)$ não atuam no sistema privado de saúde. O tempo disponibilizado para trabalho no Sistema Único de Saúde (SUS) pode ser visualizado no gráfico 8. Esse tempo é maior entre os recém-formados (gráfico 9), eles trabalham mais horas por semana do que seus colegas e proporcionalmente mais horas no SUS. 
Gráfico 8 - Total de horas semanais trabalhadas em hospitais ou serviços financiados pelo SUS.

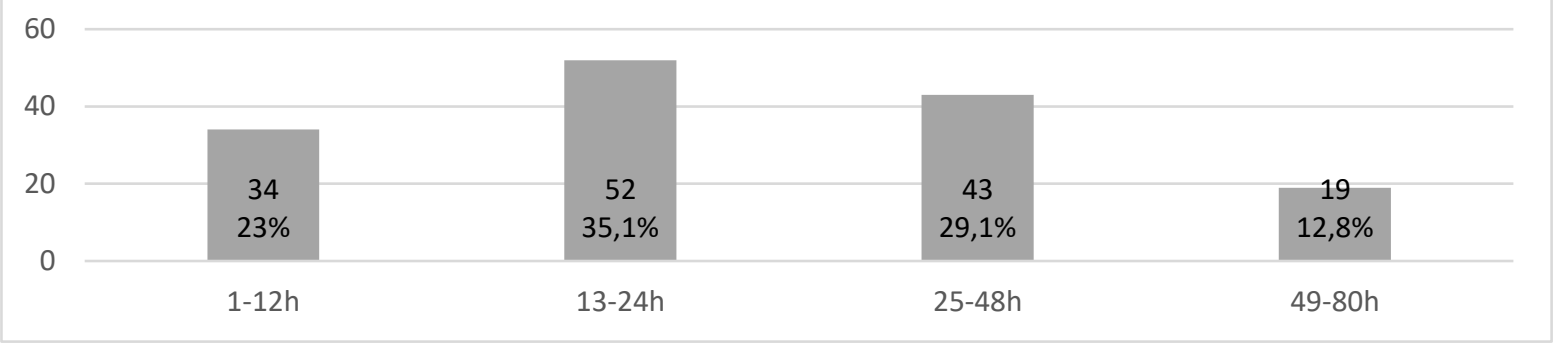

Gráfico 9 - Média do total de horas semanais trabalhadas (barra) e a proporção do total de horas trabalhadas na semana apenas no SUS (linha) de acordo com o tempo de formação

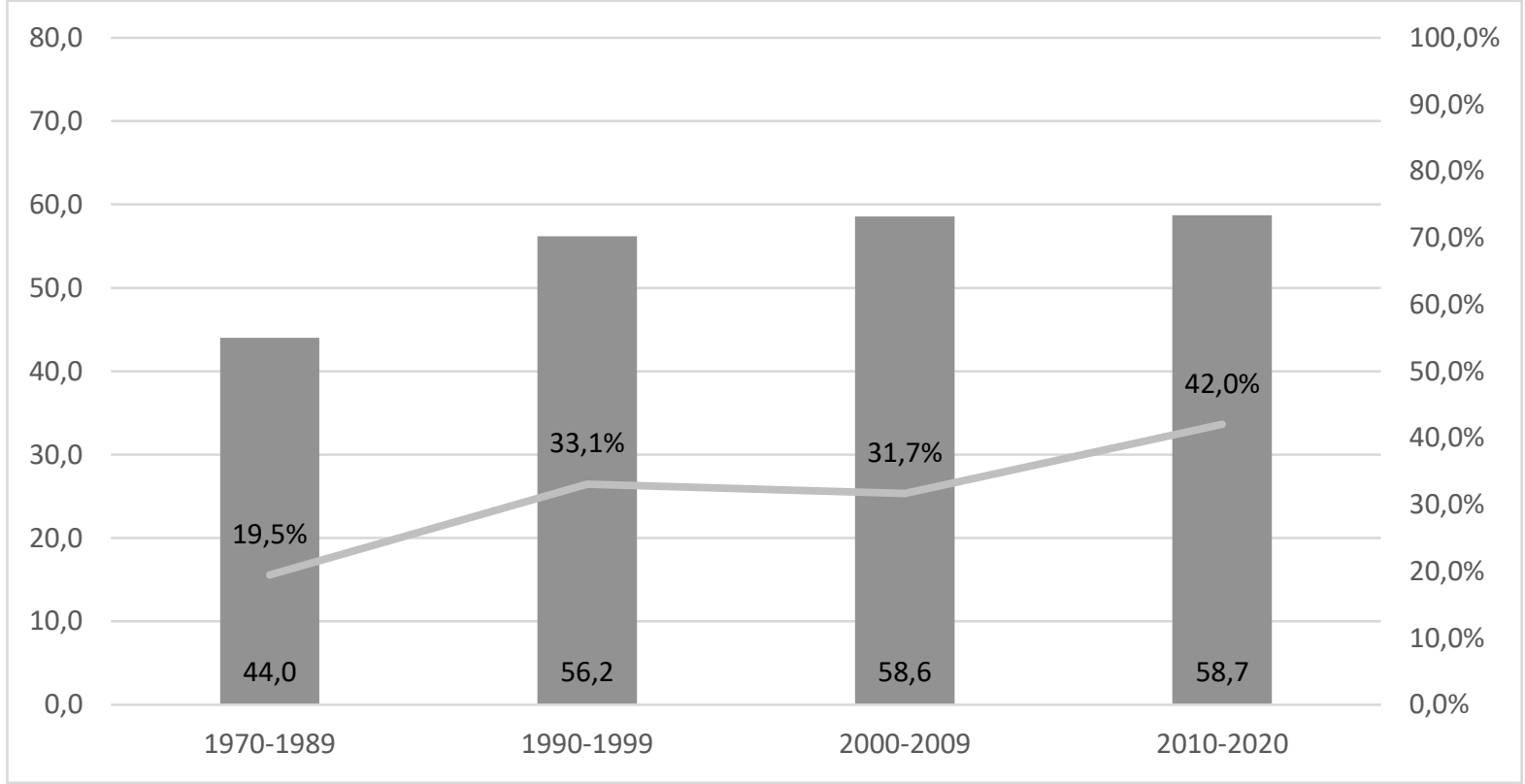

O tempo destinado ao trabalho no sistema privado é visualizado no gráfico abaixo e a proporção de horas trabalhadas com o sistema privado no gráfico seguinte.

Gráfico 10 - Total de horas semanais trabalhadas em hospitais ou consultórios privados

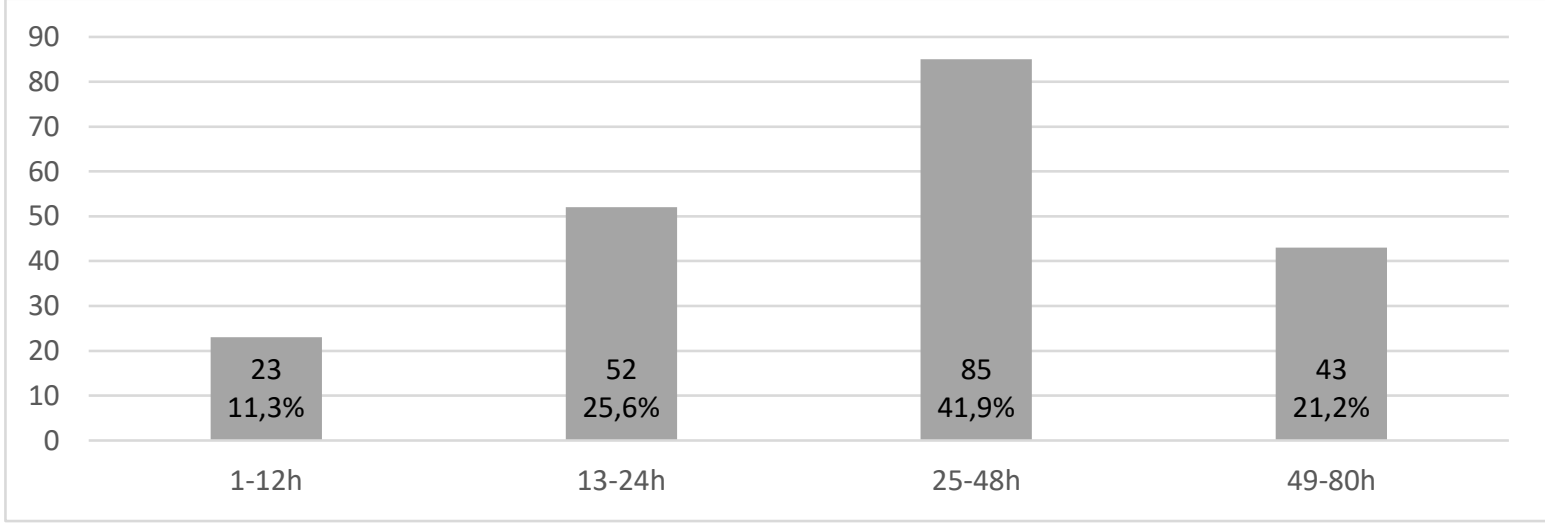


Gráfico 11 - Média do total de horas semanais trabalhadas (barra) e a proporção do total de horas trabalhadas na semana apenas no sistema privado (linha) de acordo com o tempo de formação

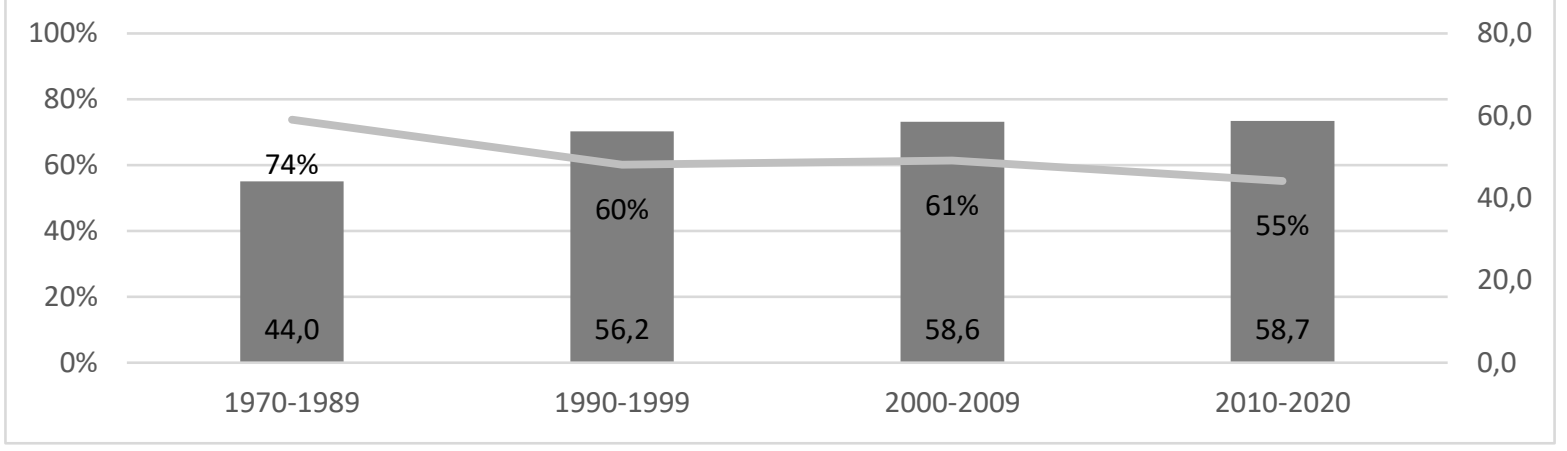

\subsubsection{Remuneração}

Neste grupo de perguntas foi questionado sobre a remuneração total mensal de cada um dos entrevistados. Tentou-se identificar também se a origem da renda é diretamente dependente da formação acadêmica e profissional ou não.

No gráfico 12 observa-se a distribuição dos egressos conforme o salário mensal total.

Gráfico 12 - Distribuição dos egressos conforme o salário mensal total.
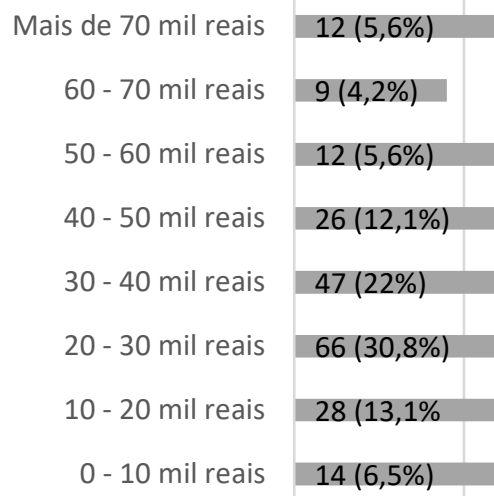

A média aproximada da renda mensal dos egressos que responderam à pesquisa foi de $R \$ 33.177,57$, valor que corresponde a 30,16 vezes o salário mínimo brasileiro atual. ${ }^{29} \mathrm{~A}$ título de comparação simples, sem explorar vieses ou poder de compra, uma pesquisa ${ }^{30} \mathrm{com}$ mais de 17 mil médicos americanos obteve como média salarial mensal dos ortopedistas de lá um valor de $U \$ 42.583,33$, que corresponde a 33,88 vezes o salário mínimo americano atual ${ }^{31}$. 
Os próximos dois gráficos analisam a renda mensal média considerando dois aspectos diferentes, o tempo de formado (gráfico 13) e onde o egresso vive atualmente (gráfico 14). A região norte, atualmente com o menor número de egressos, é a que melhor remunera. Já a região sudeste, com o maior numero de egressos, possui a menor média salarial.

Gráfico 13 - Remuneração mensal média (em $\mathrm{R} \$$ ) de acordo com o tempo de formado.

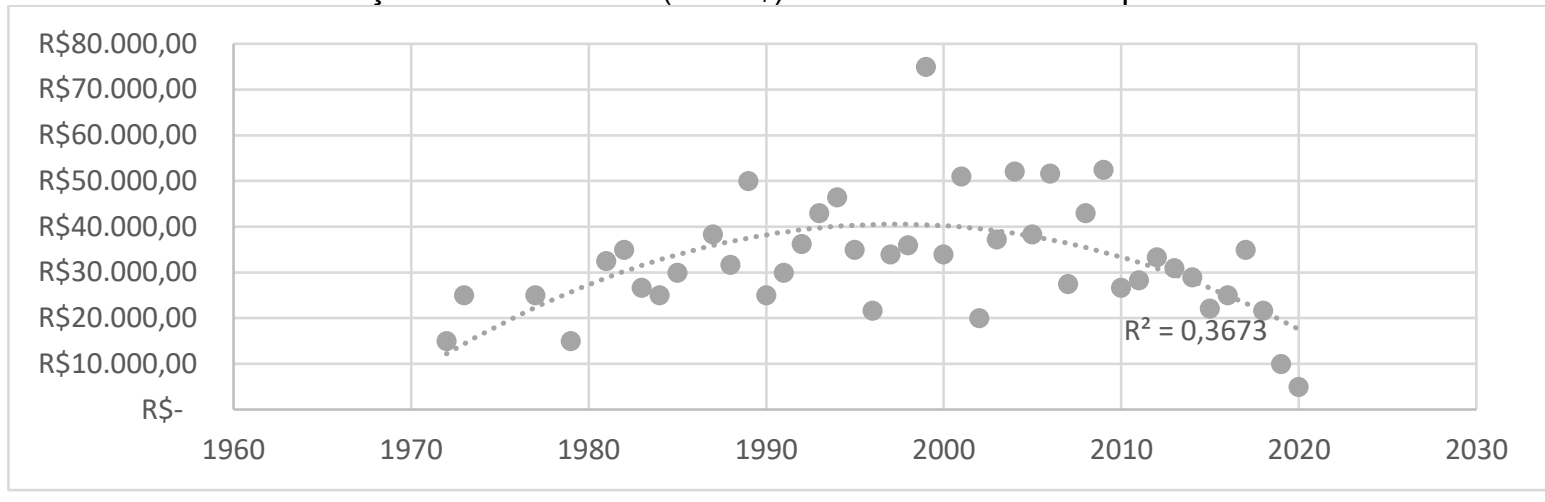

Gráfico 14 - Remuneração mensal média de acordo com o local onde vive atualmente.

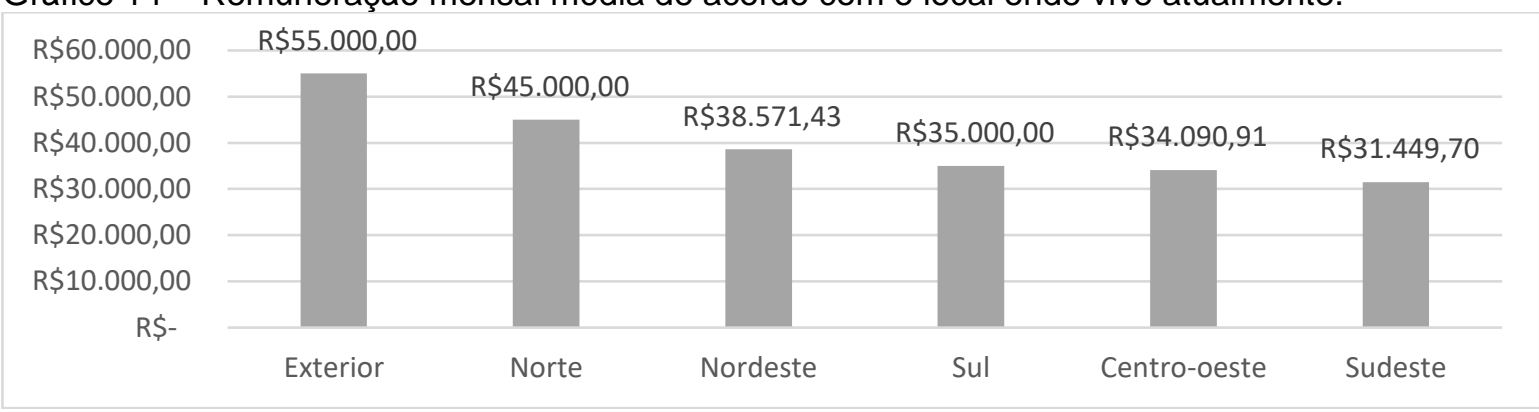

A porcentagem da renda total dos entrevistados está discriminada entre a que advém do SUS (gráfico 15), do sistema privado (gráfico 16), de convênios médicos (gráfico 17), do ensino e formação médica (gráfico 18) e de atividades não relacionadas a ortopedia (gráfico 19$)$.

Gráfico 15 - Distribuição dos egressos de acordo com a porcentagem do salário mensal total que advém de trabalho em hospitais ou serviços financiados pelo SUS.

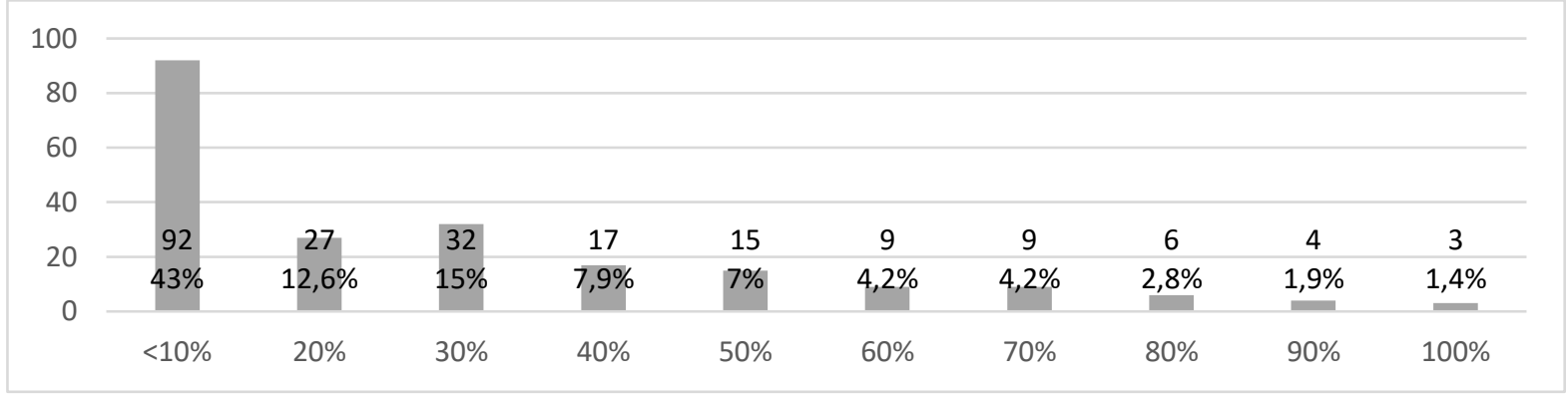


Gráfico 16 - Distribuição dos egressos de acordo com a porcentagem do salário mensal total que advém de trabalho em consultórios ou hospitais particulares

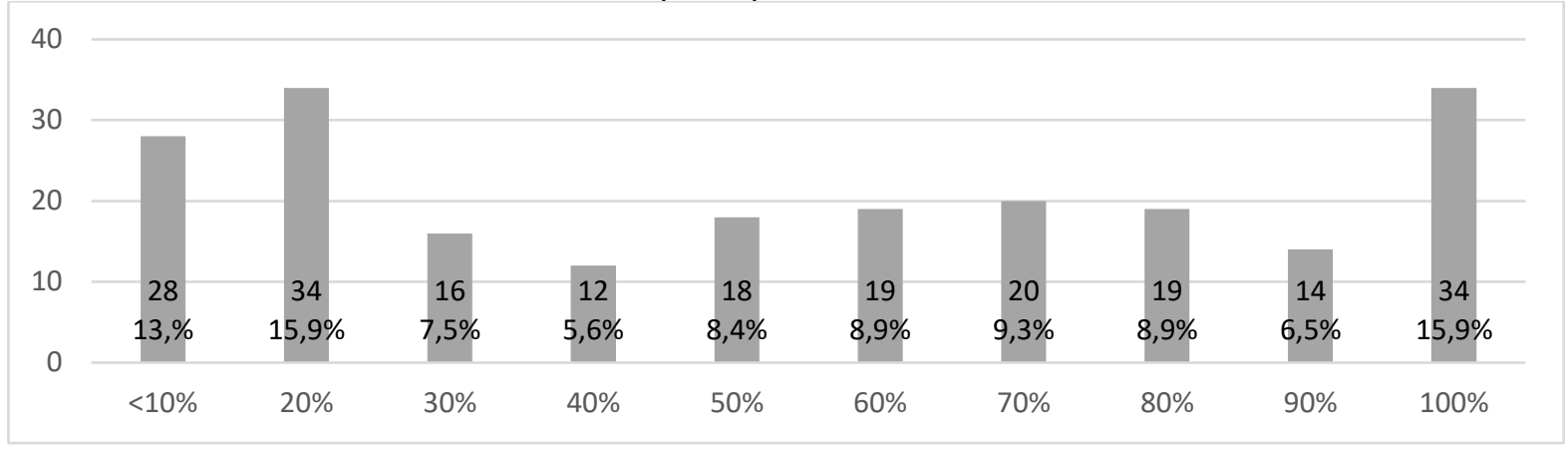

Gráfico 17 - Distribuição dos egressos de acordo com a porcentagem do salário mensal total que advém de trabalho com convênios médicos.

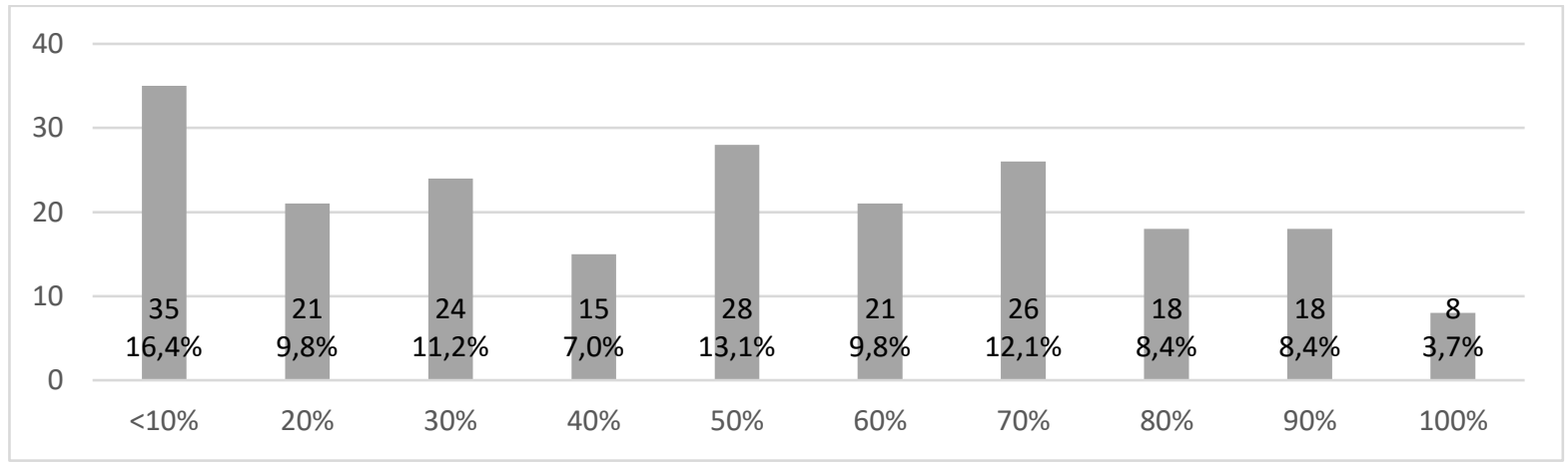

Gráfico 18 - Distribuição dos egressos de acordo com a porcentagem do salário mensal total que advém de trabalho com ensino ou formação médica.

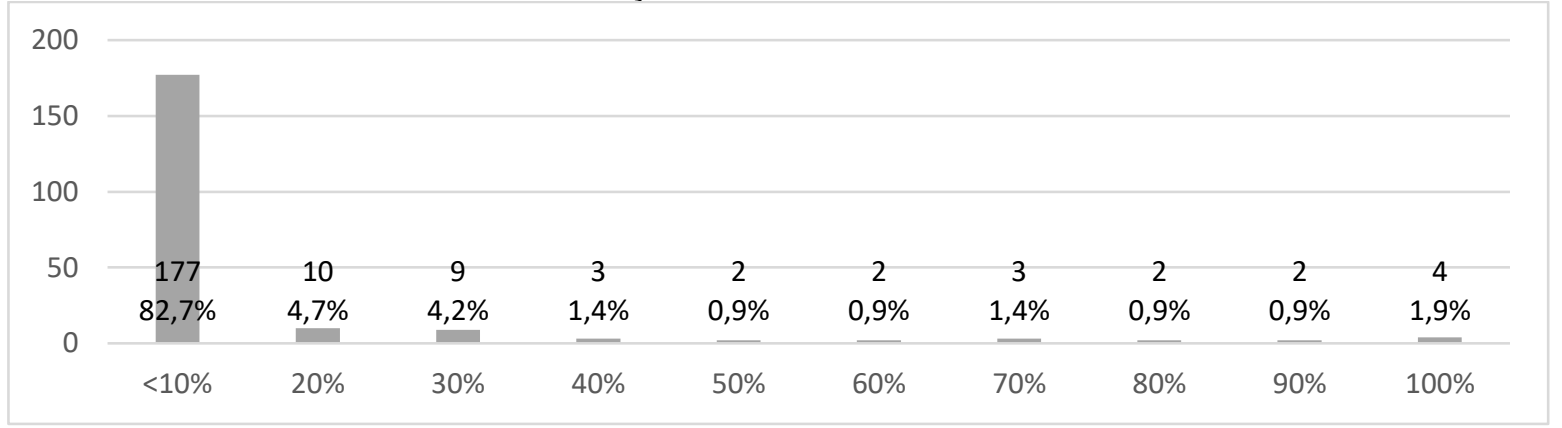

Gráfico 19 - Distribuição dos egressos de acordo com a porcentagem do salário mensal total que advém de fontes de renda não relacionadas a ortopedia

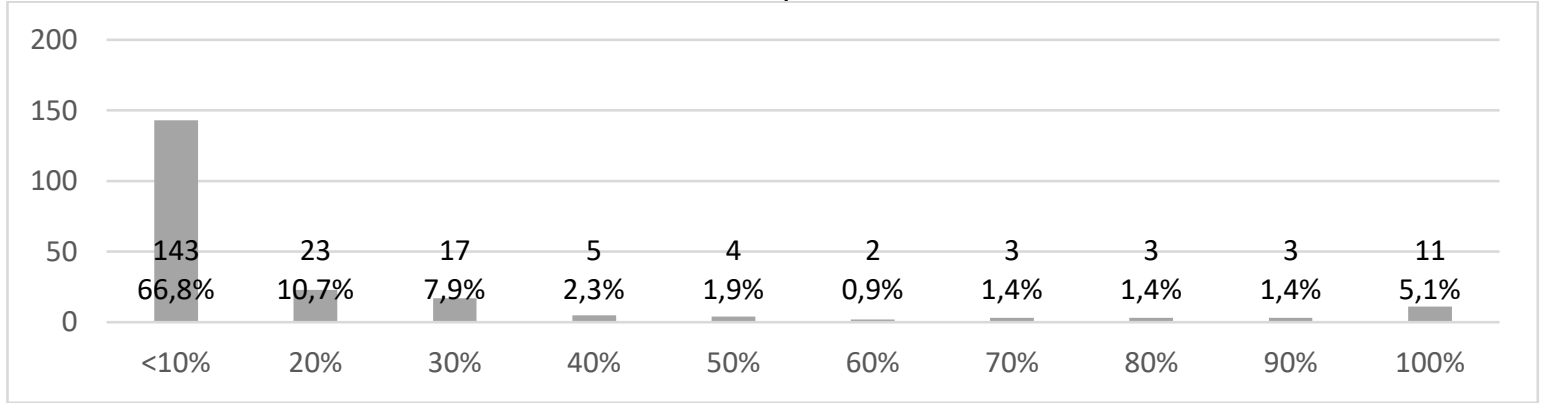


Detalhes sobre a fonte de renda não relacionada à formação como médico ortopedista são demonstrados a seguir. Possuem fonte de renda externa à ortopedia 79 pessoas (36,9\% do total), e desses, apenas 18 (22,7\%) responderam que corresponde a uma fonte de renda familiar prévia à formação como ortopedista. Dentre as atividades mais realizadas encontra-se o aluguel e venda de imóveis e a produção agropecuária (gráfico 20). O tempo disponibilizado para essas atividades pode ser visto no gráfico 21.

Gráfico 20 - Distribuição dos egressos em atividades remuneradas que não dependem da formação como médico ortopedista

Aluguel e venda de imóveis

Produção agropecuária

Clínicas / hospitais

Mercado financeiro

Medicina legal / Perícias médicas

Empresa de fabricação de produtos...

Empresa na área de alimentação

Empresa na área de moradia

Empresa na área de transportes

SAMU

Academia

Administração

Consultorias

Medicina do trabalho

Palestrante / representante

Venda de livros autorais

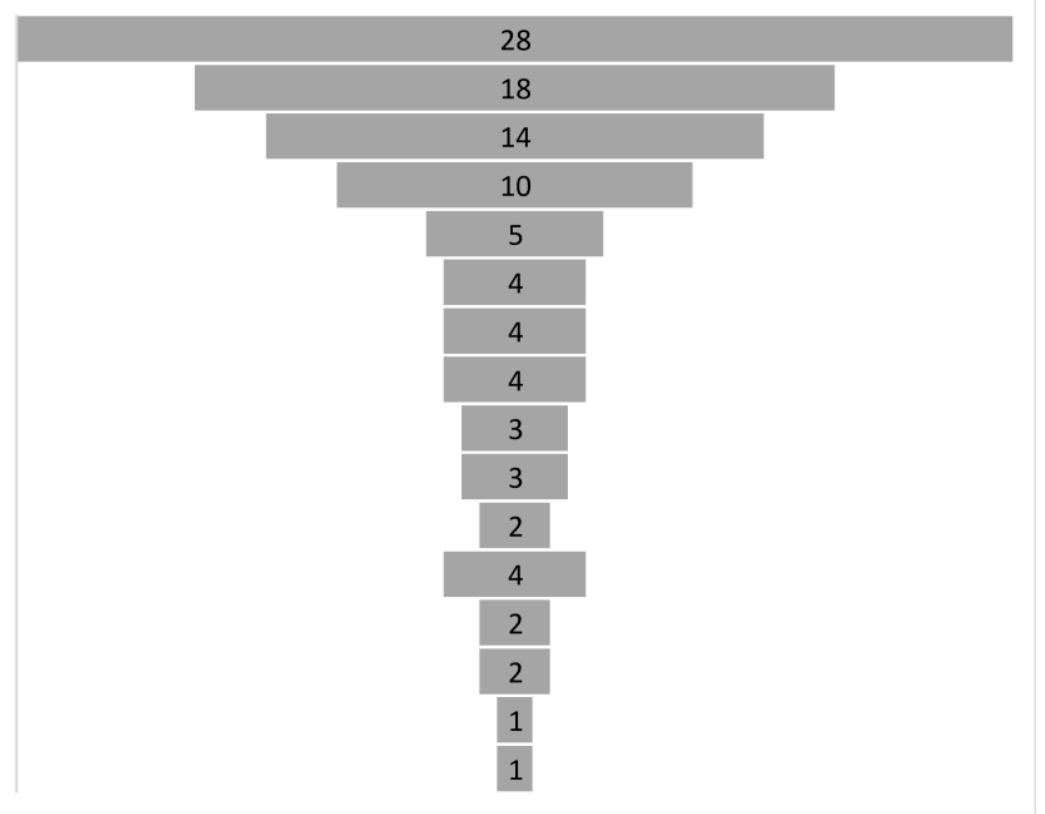

Gráfico 21 - Total de horas semanais trabalhadas em atividades remuneradas não relacionadas à ortopedia

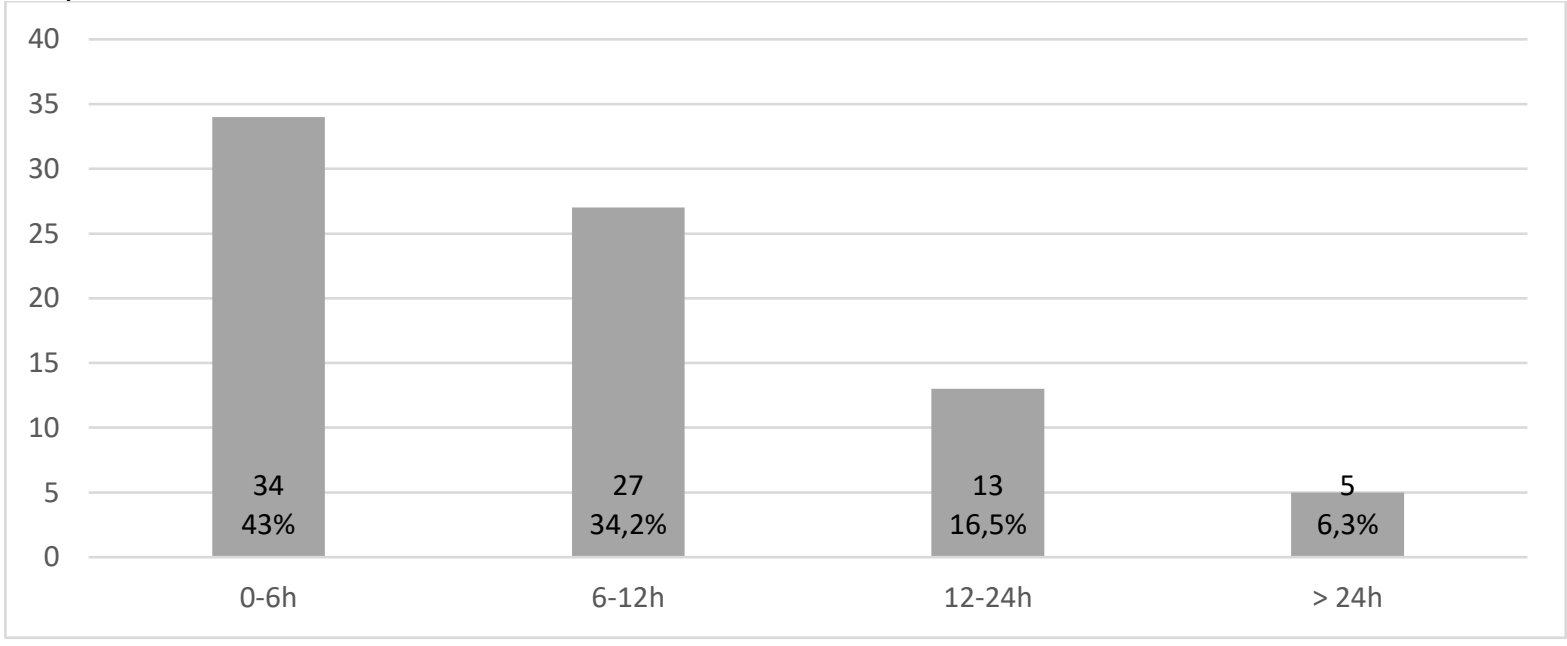




\subsubsection{Avaliação do sistema de ensino da residência médica e grau de satisfação profissional}

Os participantes responderam sete perguntas com o objetivo de avaliar aspectos do sistema de ensino durante o programa de residência: (1) carga horária de aulas teóricas, (2) discussão de casos clínicos com preceptores, (3) treinamento cirúrgico e ensino técnico, (4) número de atendimentos e variabilidade de casos, (5) capacitação para o mercado de trabalho, (6) capacitação para atendimento em nível secundário e (7) terciário. Eles também responderam duas perguntas para estimar o grau de satisfação tanto com a remuneração mensal quanto com a prática da profissão. As respostas podiam ser graduadas de 1 a 5, 1 correspondendo a "nada satisfeito" e 5 a "muito satisfeito" (Apêndice C).

Entre os aspectos que se destacaram pela boa avaliação temos, em ordem decrescente: o número de atendimentos e variabilidade dos casos, a capacitação para atendimento em nível secundário e terciário, a satisfação com a prática da ortopedia e a capacitação para o mercado de trabalho.

Os itens que chamaram a atenção pelas menores taxas de satisfação foram o treinamento cirúrgico e ensino técnico, a satisfação com remuneração mensal e, como item mais mal avaliado, a carga horária de aulas teóricas.

As respostas dessas 9 perguntas foram organizadas na tabela 2, que disponibiliza o valor médio com o respectivo desvio padrão.

Tabela 2- Análise das respostas às perguntas que utilizaram escala tipo Likert.

\begin{tabular}{cc}
\hline Número de atendimentos e variabilidade dos casos & Média e desvio padrão \\
Capacitação para atendimento em nível terciário & $4,69 \pm 0,55$ \\
Capacitação para atendimento em nível secundário & $4,51 \pm 0,69$ \\
Preparo para o mercado de trabalho & $4,27 \pm 0,80$ \\
Satisfação com suas atividades na ortopedia & $4,02 \pm 0,89$ \\
Discussão de casos clínicos com preceptores & $3,94+0,85$ \\
Treinamento cirúrgico e ensino técnico & $3,90 \pm 1,05$ \\
Satisfação com sua remuneração mensal & $3,86 \pm 1,02$ \\
Carga horária de aulas teóricas & $3,36 \pm 0,93$ \\
\hline
\end{tabular}

Na tentativa de minimizar o viés criado pela diferença do tempo de formação, foram analisadas as médias para essas mesmas perguntas, de acordo com a década em que o egresso finalizou o programa de residência. 
Os itens bem e mal avaliados variaram entre as gerações seguindo diferentes padrões, porém, é notável que a discussão de casos com preceptores, a carga horária de treinamento cirúrgico e de aulas teóricas teve seus piores resultados nas gerações mais recentes. A tabela 3 mostra as médias e desvios padrão encontradas em cada década para cada pergunta. A causa dessas variações foram sugeridas através de comentários fornecidos pelos egressos ao final do questionário.

Tabela 3- Médias e desvios padrão das respostas de acordo com a década em que foi finalizado o programa de residência.

\begin{tabular}{|c|c|c|c|c|c|}
\hline Itens avaliados & 1970-1979 & 1980-1989 & 1990-1999 & 2000-2009 & $2010-2020$ \\
\hline Atendimento terciário & $4,75 \pm 0,50$ & $4,63 \pm 0,63$ & $4,55 \pm 0,68$ & $4,59 \pm 0,64$ & $4,33 \pm 0,76$ \\
\hline Atendimento secundário & $4,50 \pm 1,00$ & $4,52 \pm 0,75$ & $4,49 \pm 0,68$ & $4,30 \pm 0,70$ & $3,86 \pm 0,91$ \\
\hline $\begin{array}{l}\text { Discussão de casos } \\
\text { clínicos com preceptores }\end{array}$ & $4,50 \pm 0,58$ & $4,19 \pm 0,88$ & $4,22 \pm 0,86$ & $3,96 \pm 0,99$ & $3,28 \pm 1,15$ \\
\hline $\begin{array}{l}\text { Número de atendimentos e } \\
\text { variabilidade dos casos }\end{array}$ & $4,25 \pm 0,50$ & $4,63 \pm 0,63$ & $4,70 \pm 0,57$ & $4,71 \pm 0,52$ & $4,72 \pm 0,53$ \\
\hline Satisfação com a profissão & $4,25 \pm 0,96$ & $4,07 \pm 0,83$ & $3,86 \pm 0,83$ & $4,00 \pm 0,85$ & $3,89 \pm 0,90$ \\
\hline $\begin{array}{l}\text { Treinamento cirúrgico e } \\
\text { ensino técnico }\end{array}$ & $4,00 \pm 1,41$ & $4,33 \pm 0,88$ & $4,26 \pm 0,72$ & $3,98 \pm 0,93$ & $3,04 \pm 1,00$ \\
\hline Carga horária teórica & $3,75 \pm 0,96$ & $3,63 \pm 1,15$ & $3,43 \pm 1,01$ & $2,67 \pm 1,04$ & $2,18 \pm 1,12$ \\
\hline $\begin{array}{l}\text { Preparo para o mercado de } \\
\text { trabalho após o Programa } \\
\text { de Residência Médica }\end{array}$ & $3,50 \pm 1,73$ & $4,22 \pm 0,75$ & $4,26 \pm 0,59$ & $4,18 \pm 0,79$ & $3,53 \pm 1,07$ \\
\hline $\begin{array}{l}\text { Satisfação com a } \\
\text { remuneração mensal }\end{array}$ & $3,50 \pm 1,00$ & $3,26 \pm 0,59$ & $3,44 \pm 0,97$ & $3,47 \pm 0,91$ & $3,19 \pm 1,03$ \\
\hline
\end{tabular}

No gráfico 22 observa-se a sobreposição da remuneração média mensal com a satisfação em relação a esse tópico. Obteve-se evidência, sem grande surpresa, de que são fatores diretamente proporcionais, mais evidente nos dois extremos, sendo que a diferença entre a média salarial de quem respondeu estar "nada satisfeito" e "muito satisfeito" com sua própria remuneração foi de mais de $\mathrm{R} \$ 30.000,00$.

Gráfico 22 - Total de horas semanais trabalhadas em atividades remuneradas não relacionadas à ortopedia

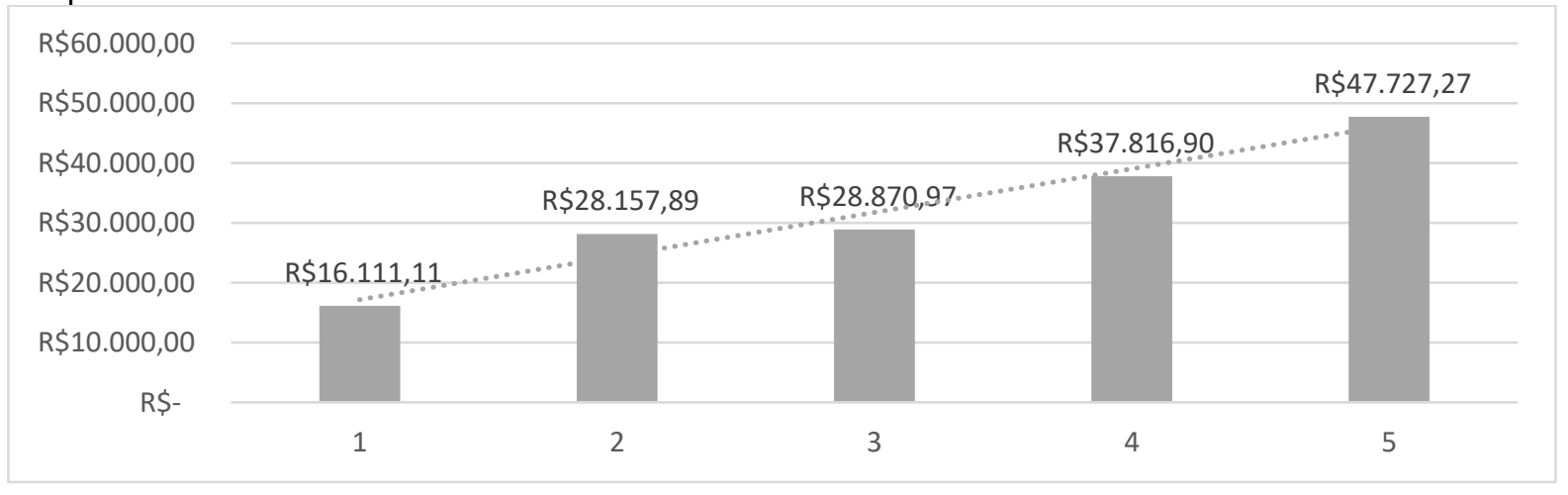


A sobreposição das médias salariais com as médias de satisfação com a profissão e com a remuneração de cada especialidade se encontra no gráfico abaixo. Atenção é dada ao fato de que a ortopedia oncológica, apesar da menor média salarial entre os subespecialistas recebeu a maior nota em relação a satisfação com a profissão. Já os subespecialistas em cirurgia do quadril apesar da terceira melhor remuneração apresentaram as notas mais baixas em relação a satisfação. Observase ainda que aqueles que optaram por não fazer subespecialidade possuem boa média salarial e bons níveis de satisfação.

Gráfico 23 - Remuneração mensal média por especialidade e satisfação média com a remuneração e com a profissão

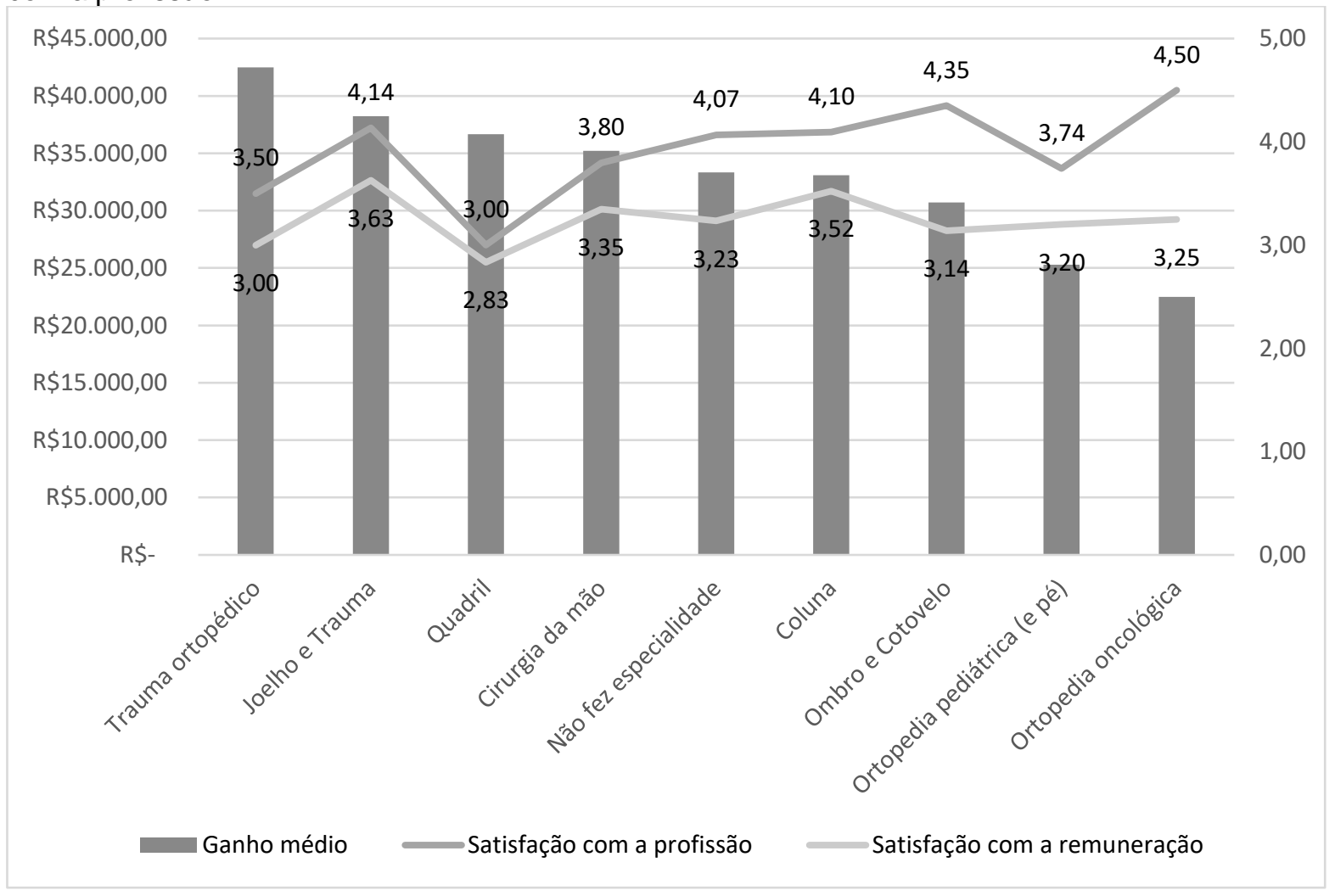

Na última fase do questionário existiam perguntas que avaliavam indiretamente a satisfação pessoal dos participantes com as escolhas realizadas durante a fase de formação profissional. Foi perguntado sobre a possibilidade de escolher outra residência médica caso estivessem no último ano da faculdade de medicina e sobre a possibilidade de fazer outra subespecialização após terminar a residência de ortopedia e traumatologia, estas respostas são visualizadas nas tabelas 4 e 5 . 
Tabela 4- PRM que o egresso teria escolhido hoje

\begin{tabular}{lll}
\hline Programa de residência & $\mathrm{N}$ & $\%$ \\
\hline Ortopedia & 173 & 80,8 \\
Radiologia & 6 & 2,8 \\
Anestesiologia & 5 & 2,3 \\
Cirurgia plástica & 3 & 1,4 \\
Cirurgia vascular & 3 & 1,4 \\
Oftalmologia & 3 & 1,4 \\
Ginecologia e obstetrícia & 2 & 0,9 \\
Medicina do esporte & 2 & 0,9 \\
Oncologia & 2 & 0,9 \\
Patologia & 2 & 0,9 \\
Dor & 1 & 0,5 \\
Fisiatria & 1 & 0,5 \\
Psiquiatria & 1 & 0,5 \\
Medicina intensiva & 1 & 0,5 \\
Não faria medicina & & 1,4 \\
Não sabe ou não quis responder & 3 & 2,8 \\
\hline
\end{tabular}

Tabela 5- Subespecialização que o egresso teria escolhido hoje

\begin{tabular}{lll}
\hline Subespecialização & N & $\%$ \\
\hline Cirurgia do joelho (e trauma) & 63 & 29,4 \\
Cirurgia da mão & 37 & 17,3 \\
Cirurgia de coluna & 29 & 13,6 \\
Ombro e cotovelo & 28 & 13,1 \\
Ortopedia pediátrica (e pé) & 28 & 13,1 \\
Cirurgia do quadril & 14 & 6,5 \\
Trauma ortopédico & 10 & 4,7 \\
Ortopedia oncológica & 8 & 3,7 \\
Pé e tornozelo & 6 & 2,8 \\
Dor & 2 & 0,9 \\
Não sabe ou nenhuma & & \\
\hline
\end{tabular}

$\mathrm{Na}$ área destinada a sugestões para melhoria do programa de residência foi utilizado um espaço livre e sem limite de caracteres para as respostas. Nessa sessão a resposta não era obrigatória, mesmo assim, 169 pessoas se manifestaram. Cabe salientar que as sugestões foram adicionadas sem correlacioná-las com o ano em que o egresso participou do PRM e que muitas adaptações ao método de ensino já foram implementadas, especialmente nos últimos anos. 
Tabela 6 - Sugestões mais prevalentes para melhoria do PRMOT

\begin{tabular}{ll}
\hline Sugestões & $\mathrm{N}$ \\
\hline Aumentar carga horaria de aulas teóricas & 82 \\
Aumento da carga horária de treinamento cirúrgico & 29 \\
Discussões de casos clínicos em todas as subespecialidades & 17 \\
Sistema de distribuição de procedimentos cirúrgicos de acordo com complexidade & 10 \\
Maior número e disponibilidade dos preceptores/docentes & 9 \\
Orientação e preparo para o mercado de trabalho & 8 \\
Mais procedimentos cirúrgicos de menor complexidade & 6 \\
Aplicação de provas & 6 \\
Aumentar o tempo de residência & 3 \\
Curso teórico-prático em cadáver & 3 \\
Diminuição da carga horária semanal & 3 \\
Laboratórios para treinamento & 3 \\
Mais incentivo à pesquisa & 2 \\
Associar outras especialidades às discussões clínicas (radiologia e patologia, por & 1 \\
exemplo) & \\
Diminuir carga horária de atendimento ambulatorial & 1 \\
Protocolos de padronização de tratamento e seguimento das afecções mais prevalentes & 1 \\
Programa de ensino contemplando todo o programa da prova de título distribuídos de & 1 \\
acordo com a complexidade e com o ano de residência & \\
Não alterariam o programa & 18 \\
\hline
\end{tabular}

Dentre as mais variadas opiniões (tabela 6) a que obteve maior prevalência foi o pedido pelo aumento da carga horária de aulas teóricas durante o programa de residência. A resolução da CNRM № 02 de 17 de maio de 2006 dispõe sobre requisitos mínimos dos Programas de Residência Médica e dá outras providências.

Art. 9․ Os programas de Residência Médica serão desenvolvidos com 80 a $90 \%$ da carga horária, sob a forma de treinamento em serviço, destinando-se 10 a $20 \%$ para atividades teórico-complementares.

$\S$ 1‥ Entende-se como atividades teórico-complementares: sessões anátomo-clínicas, discussão de artigos científicos, sessões clínicoradiológicas, sessões clínico-laboratoriais, cursos, palestras e seminários. ${ }^{32}$

O uso de aulas teóricas como método de ensino é apenas um dos tipos possíveis de atividade teórica disposto na resolução e é controverso na literatura. Um estudo de coorte com 195 residentes de medicina interna na Clínica Mayo, nos Estados Unidos da América (EUA), constatou que aulas as teóricas são equivalentes ao uso da ferramenta UpToDate ${ }^{\circledR}$ durante 20 minutos por semana e que o uso de ambas as técnicas esteve associado ao melhor desempenho em testes oficiais. ${ }^{33} \mathrm{Em}$ contrapartida, um estudo mais recente com residentes de radiologia, também dos EUA, demonstrou não haver diferença em avaliações de performance clínica e teórica entre os residentes que frequentavam ou não as aulas teóricas oferecidas pelo programa. $^{34}$ 
Várias tentativas já foram realizadas para o estabelecimento e disponibilização de conteúdo teórico ao decorrer dos anos. É verdade também que em algumas áreas do PRMOT as aulas são oferecidas, mas nem sempre com quórum satisfatório.

Outro aspecto que gerou insatisfação do ponto de vista dos egressos foi o treinamento técnico e cirúrgico. Foi a terceira pergunta mais mal avaliada na parte objetiva, com média de $3,37 \pm 1,12$. Na sessão de sugestões para melhoria do programa foi segundo tópico mais citado. Apesar disso, o preparo para o mercado de trabalho teve boa avaliação, com média de 3,76 $\pm 0,99$.

A Resolução da CNRM no 22, de 8 de abril de 2019 aprova a matriz de competências dos Programas de Residência Médica em Ortopedia e Traumatologia.

OBJETIVOS ESPECÍFICOS [...]

9. Planejar e executar as técnicas cirúrgicas ortopédicas nos diferentes graus de complexidade, progressivamente, durante os três anos de treinamento em ortopedia e traumatologia, prevendo e solucionando as possíveis complicações; ${ }^{35}$

Estudos internacionais comprovam que a preocupação em relação ao treinamento cirúrgico do residente de ortopedia não é uma particularidade dos nossos egressos. Em um estudo alemão, menos de $10 \%$ dos procedimentos de artroplastia de joelho ou artroscopia de ombro eram realizadas pelos residentes..$^{36}$ Outro estudo compartilhou os procedimentos realizados por residentes durante os 6 anos de formação no Reino Unido e Irlanda e chamou atenção para uma ferramenta chamada eLogbook, na qual o residente registra o histórico dos procedimentos já realizados por ele. Essa ferramenta facilita a análise e percepção de áreas onde o residente tem menos ou mais experiência e, ao mesmo tempo, dá aos preceptores um feedback do ensino técnico. ${ }^{37}$

O detalhamento e trajetória profissional do egresso de um programa de residência médica tem se demonstrado uma importante ferramenta de avaliação do ensino médico. Os altos índices de satisfação pessoal e profissional e as altas taxas de egressos envolvidos com ensino médico demonstraram o impacto de uma boa formação profissional e acadêmica na instituição. 
CONCLUSÃO 


\section{CONCLUSÃO}

É possível afirmar que o estudo conseguiu caracterizar o perfil dos médicos egressos do PRMOT do HC-FMRP-USP. Descreveu detalhadamente o perfil sociodemográfico, formação acadêmica e a trajetória profissional dos egressos incluindo detalhes sobre remuneração e satisfação com a profissão.

O sistema de ensino foi avaliado sob a perspectiva dos egressos. Consideraram pontos fortes do programa: o número de atendimentos e a variabilidade de casos clínicos, a capacitação para o atendimento em nível secundário e terciário e o bom preparo para o mercado de trabalho. Criticaram e trouxeram alertas para pontos específicos, sugerindo principalmente o aumento da carga horária de aulas teóricas e do treinamento cirúrgico sob supervisão. 


\section{REFERÊNCIAS}




\section{REFERÊNCIAS *}

1- BRASIL. Ministério da Educação e Cultura. Decreto № 80.281 , de 5 de setembro de 1977. Regulamenta a Residência Médica e cria a Comissão Nacional de Residência Médica e dá outras providências. Diário Oficial da União, Brasília, DF, 06 set. 1977. Seção 1, p. 11787. Disponível em: <http://portal.mec.gov.br/sesuarquivos/pdf/leg.pdf>. Acesso em 13 jul. 2019.

2- NUNES, M. P. T. et al. A Residência Médica, a preceptoria, a supervisão e a coordenação. Cadernos da ABEM, Rio de Janeiro, v. 7, n. 1, p. 35-40, 2011a. Disponível em: <https://website.abem-educmed.org.br/wp-content/uploads/201909CadernosABEM_Vol01.pdf>. Acesso em 15 jul. 2019.

3- NUNES, M. P. T. et al. Distribuição das vagas de Residência Médica e de médicos nas regiões do país. Cadernos da ABEM, Rio de Janeiro, v. 7, n. 1, p. 28-34, 2011b. Disponível em: <https://website.abem-educmed.org.br/wpcontent/uploads/2019/09/CadernosABEM_Vol07.pdf>. Acesso em 15 jul. 2019.

4- KOCH, V. H. K.; DORIA FILHO, U.; BOLLELA, V. R. Avaliação do programa de residência médica do Departamento de Pediatria da Faculdade de Medicina da Universidade de São Paulo. Revista Brasileira de Educação Médica, Rio de Janeiro, v. 35, n. 4, p. 454-9, 2011. Disponível em: <https://www.scielo.br/pdf/rbem-v35n4/a03v35n4.pdf>. Acesso em 13 jul. 2019.

5- SENGER, M. H. et al. Trajetória profissional de egressos do curso de Medicina da Universidade de Campinas (Unicamp), São Paulo, Brasil: o olhar do exaluno na avaliação do programa. Interface (Botucatu), Botucatu, v. 22, supl. 1, p. 1443-1455, 2018. Disponível em: <https://www.scielo.br/pdf/icse/v22s1/1807-5762icse-22-s1-1443.pdf>. Acesso em 15 jul. 2019.

6- ARTINO A. R. Jr. et al. Developing questionnaires for educational research: AMEE guide $n^{\circ}$ 87. Medical Teacher, Dundee, v. 36, p. 463-74, 2014. 
Disponível em: <https://www.ncbi.nlm.nih.gov/pmc/articles/PMC4059192/pdf/MTE36-463.pdf>. Acesso em 15 jul. 2019.

7- $\quad$ PHILLIPS A. W.; REDDY S.; DURNING S. J. Improving response rates and evaluating nonresponse bias in surveys: AMEE guide No.102. Medical Teacher, Dundee, v. 28, p. 217-28, 2016. Disponível em: <https://www.ncbi.nlm.nih.govpubmed/26648511>. Acesso em 15 jul. 2019.

8- $\quad$ SAKAI M. H.; CORDONI L. Jr. Os egressos da Medicina da Universidade Estadual de Londrina: sua formação e prática médica. Espaço para a Saúde, Londrina, v. 6, n. 1, p. 34-47, 2004.

9- CAOVILLA F. et al. Perfil do médico egresso do curso de Medicina da Universidade Luterana do Brasil (ULBRA). Revista AMRIGS, Porto Alegre, v. 52, n. 2, p. 103-9, 2008.

10- CASTELLANOS M. E. P. et al. Perfil dos egressos da Faculdade de Medicina do $A B C$ : o que eles pensam sobre atenção primária em saúde? Arquivo Brasileiro de Ciências de Saúde, Santo André, v. 34, n. 2, p. 71-9, 2009. Disponível em: <https://www.portalnepas.org.br/abcs/article/view/130>. Acesso em 01 ago. 2019.

11- IGLESIAS, A. G. Perfil dos alunos egressos do curso de medicina da Faculdade de Medicina de Ribeirão Preto da Universidade de São Paulo (FMRPUSP). 2016. Tese (Doutorado em Clínica Médica) - Faculdade de Medicina de Ribeirão Preto, Universidade de São Paulo, Ribeirão Preto, 2016. Disponível em: < https://www.teses.usp.br/teses/disponiveis/17/17138/tde-05122016-114736/ptbr.php>. Acesso em: 01 ago. 2019.

12- EZEQUIEL O. S. et. al. Geographical distribution of medical graduates from a public university. Revista da Associação Médica Brasileira, São Paulo, v. 63, n. 6, p. 512-520, 2017. Disponível em: <https://www.scielo.br/pdf/ramb/v63n6/01044230-ramb-63-06-0512.pdf>. Acesso em 01 ago. 2019.

13- UNIVERSIDADE DE SÃO PAULO. História do departamento de Ortopedia e Traumatologia da Faculdade de Medicina de Ribeirão Preto da Universidade de São Paulo. Departamento de Biomecânica Medicina e Reabilitação 
do Aparelho Locomotor Disponível em: <http://ral.fmrp.usp.br/new-ortopedia.html>. Acesso em 03 mar. 2019.

14- SALGANIK, M. J. Variance estimation, design effects, and sample size calculations for respondent-driven sampling. Journal of Urban Health: Bulletin of the New York Academy of Medicine. v.83, p. 98-112, 2006.

15- SALGANIK, M. J.; HECKATHORN, D. D. Sampling and estimation in hidden populations using respondent-driven sampling. Sociological Methodology. $v$. 34, p. 193-240, 2004.

16- ATKINSON, R.; FLINT, J. Acessing hidden and hard-to-reach populations: Snowball research strategies. Social Research Update. v.33, p. 1-4, Department of Sociology, University of Surrey, 2001.

17- VAN MOL, C. Improving web survey efficiency: The impact of an extra reminder and reminder content on Web survey response. International Journal of Social Research Methodology, v. 20, n. 4, p. 317-327, 2017. Disponível em: $<$ https://www.tandfonline.com/doi/full/10.1080/13645579.2016.1185255>. Acesso em 09 fev. 2020.

18- DALMORO, M.; VIEIRA, K. M. Dilemas na construção de escalas tipo Likert: o número de itens e a disposição influenciam nos resultados? Revista Gestão Organizacional, Chapecó, v. 6, p. 161-174, 2013. Disponível em: $<$ https://bell.unochapeco.edu.br/revistas/index.php/rgo/article/view/1386>. Acesso em 09 fev. 2020.

19- BRASIL. Resolução ํㅜ 466, de 12 de dezembro de 2012. Dispõe sobre diretrizes e normas regulamentadoras de pesquisas envolvendo seres humanos. Diário Oficial da União, Brasília, DF, 13 jun. 2013. Disponível em: $<$ http://bit.ly/1mTMIS3 >. Acesso em 09 fev. 2020.

20- SCHEFFER, M. et al. Demografia Médica no Brasil 2020. São Paulo: FMUSP, CFM, 2020. 312 p. ISBN: 978-65-00-12370-8. 
21- RODRIGUES, E. T. Egressos de programas de residência em Medicina de Família e Comunidade do estado de São Paulo, 2000-2009. 2012. 147 p. Dissertação (Mestrado) - Faculdade de Medicina de Ribeirão Preto, Universidade de São Paulo, Ribeirão Preto, 2012. Disponível em: <https://teses.usp.br/teses/disponiveis/17/17139/tde-08102015-095824/pt-br.php>. Acesso em 09 fev. 2020.

22- $\quad$ FARIAS, E. R. Onde estão e o que fazem os egressos da residência de Medicina de Família e Comunidade do Murialdo? 2005. 79 f. Dissertação (Mestrado em Saúde Coletiva) - Universidade Luterana do Brasil, Canoas, 2005.

23- MACHADO, M. H. Perfil dos médicos e enfermeiros do Programa Saúde da Família no Brasil: relatório final. Brasília: Ministério da Saúde, 2000.

24- MACIEL, E. L. N. et al. Avaliação dos egressos do curso de especialização em Saúde da Família no Espírito Santo, Brasil. Ciência \& Saúde Coletiva, Rio de Janeiro, v. 15, n. 4, p. 2021-2028, 2010.

25- BASÍLIO N. et al. Portuguese primary care physician's response rate in surveys: A systematic review. Revista da Associação Médica Brasileira, São Paulo, v. 64 , n. 3, p. 272-280, 2018.

26- FINCHAM J. E. Response rates and responsiveness for surveys, standards, and the Journal. American Journal of Pharmaceutical Education, Arlington; v. 72, n. 2, p. 43, 2008. Disponível em: <https://www.ncbi.nlm.nih.gov/pmcarticles/PMC2384218/pdf/ajpe43.pdf>. Acesso em 09 mar. 2020.

27- LANDIS R. J.; KOCH G. G. The measurement of observer agreement for categorical data. Biometrics, Chichester, v. 33, p. 159-74, 1977.

28- HAIR, J. F. Jr.; ANDERSON, R. E.; TATHAM, R. L.; BLACK, W. C. Análise Multivariada de Dados. 5a edição. Bookman Editora, São Paulo, 1998

29- BRASIL. Medida provisória no 1.021, de 30 de dezembro de 2020. Dispõe sobre o valor do salário mínimo a vigorar a partir de 1ํ de janeiro de 2021. 
Diário Oficial da União, Poder Executivo, Brasília, DF, 31 dez. 2020. Ed 250. Seção 1, p. 1.

30- Medscape Physician Compensation Report 2020. Disponível em: <https://www.medscape.com/slideshow/2020-compensation-overview-6012684>. Acesso em 17 nov. 2020.

31- US. DEPARTMENT OF LABOR. Minimum Wage. Disponível em: <https://www.dol.gov/general/topic/wages/minimumwage>. Acesso em 17 nov. 2020.

32- BRASIL. Ministério da Educação e Cultura. Resolução CNRM oo 02/2006. Dispõe sobre requisitos mínimos dos Programas de Residência Médica e dá outras providências. Diário Oficial da União, Brasília, DF, 19 de mai. 2006. Seção 1, p. 23-36. Disponível em: <http://portal.mec.gov.br/par/247-programas-e-acoes1921564125/residencia-medica-2137156164/13079-resolucao-residencia-medica>. Acesso em 09 mar. 2020.

33- MCDONALD F. S.; ZEGER S. L.; KOLARS J. C. Factors associated with medical knowledge acquisition during internal medicine residency. Journal of General Internal Medicine, Alexandria, v. 22, n. 7, p. 962-968, 2007. Disponível em: <https://www.ncbi.nlm.nih.gov/pmc/articles/PMC2219722/>. Acesso em 09 mar. 2020.

34- MEYER N. B. et al. Lack of measurable clinical or knowledge gains from resident participation in noon conference. Academic Radiology, Philadelphia, v 25. p. 719-726, 2018.

35- BRASIL. Ministério da Educação e Cultura. Resolução CNRM no 22/2019. Aprova a matriz de competências dos Programas de Residência Médica em Ortopedia e Traumatologia. Diário Oficial da União, Brasília, DF, 11 de abr. 2019. Seção 1, p. 213. Disponível em: <http://portal.mec.gov.br/index.php?optioncom_docman\&viewdownload\&alias=111661-22-resolucao-n-22-de-8-de-abril-de2019-ortopedia-e-traumatologia\&category_slug=abril-2019-pdf\&ltemid=30192>. Acesso em 10 mar. 2020. 
36- LÜRING C. et. al. Die operative Weiterbildung an deutschen orthopädischen und traumatologischen Kliniken. Zeitschrift fur Orthopadie und Unfallchirurgie, Germany, v.148, p. 466-70, 2010

37- JAMESON S. S. et. al. Trauma experience in the UK and Ireland: analysis of orthopaedic training using the FHI eLogbook. Injury. v. 39, n. 8, p. 844852. 10.1016/j.injury.2008.03.030. Disponível em: < https://www.sciencedirect.comscience/article/abs/pii/S0020138308001563 >. Acesso em: 10 mar. 2020. 
APÊNDICES 


\section{APÊNDICES}

\section{APÊNDICE A - TERMO DE CONSENTIMENTO LIVRE E ESCLARECIDO}

Você está sendo convidado a participar da pesquisa Perfil do egresso e avaliação do Programa de Residência Médica em Ortopedia e Traumatologia do Hospital das Clínicas da Faculdade de Medicina de Ribeirão Preto da Universidade de São Paulo, de responsabilidade do pesquisador Bruno Adona Ribeiro, mestrando do programa de Mestrado Profissional em Medicina desta instituição e médico residente de Ortopedia e Traumatologia Hospital das Clínicas da Faculdade de Medicina de Ribeirão Preto da Universidade de São Paulo sob orientação do Professor Dr. Edgard Eduard Engel.

A pesquisa será realizada com base nas respostas fornecidas pelos participantes no questionário eletrônico disponibilizado. Este questionário é composto por perguntas abertas e fechadas e para seu preenchimento completo não são necessários mais do que 10 minutos do seu tempo. Você poderá enviar suas respostas no máximo até o dia 31 de dezembro de 2019.

Objetivos gerais: Caracterizar o perfil sociodemográfico dos médicos egressos do Programa de Residência Médica em Ortopedia e Traumatologia (PRMOT) do Hospital das Clínicas da Faculdade de Medicina de Ribeirão Preto da Universidade de São Paulo. Analisar as virtudes e deficiências do PRMOT sob o ponto de vista dos egressos. Compreender a formação de recursos humanos em Ortopedia e Traumatologia e colaborar com os programas de residência nesta área.

Objetivos específicos: Descrever a atuação profissional dos egressos: dados sociodemográficos, formação acadêmica, situação profissional atual, engajamento no Sistema Único de Saúde, engajamento em instituições de educação médica, trajetória profissional após a Residência e acesso à publicação técnico-científica.

O presente termo de consentimento ficará disponível no início do questionário e só será incluído no estudo se a caixa de verificação de consentimento explícito em participar da pesquisa estiver marcado.

Riscos: o questionário aplicado possui perguntas abertas e fechadas e os riscos consistem em uma eventual quebra de sigilo, sendo, portanto, um risco inerente ao tipo da pesquisa realizada. Acreditamos que o questionário, mesmo tendo sido 
elaborado de forma concisa e seguindo orientações da literatura nacional e internacional, possa ser considerado demorado pelo entrevistado, causando certo desconforto durante seu preenchimento.

Benefícios: possibilidade de avaliar o Programa de Residência Médica em Ortopedia e Traumatologia do HC-FMRP-USP e melhorar os aspectos cabíveis.

Direito de confidencialidade ao participante da pesquisa: direito de não identificação e de manutenção do caráter confidencial da informação com relação à privacidade. As informações serão coletadas de forma que a identificação do sujeito só será possível pela decodificação da tabela mestre. Além disso os dados serão mantidos criptografados. Os autores se comprometem à não divulgar ou expor as informações coletadas durante ou após a realização da pesquisa. Os pesquisadores também se comprometem a impedir completamente à correlação dos dados divulgados com os sujeitos individualmente. Salvo a informação que são egressos do programa de residência em estudo.

Garantia de acesso: você deverá guardar uma via deste TCLE. Em qualquer etapa da pesquisa, você poderá contatar-me pelo telefone número 16-98262-1713 ou e-mail baribeiro@fmrp.usp.br, para esclarecimento de eventuais dúvidas acerca de procedimentos, riscos, benefícios, etc. Meus dados para contato também estarão contidos no início do questionário e no convite para participação desta pesquisa.

Garantia de liberdade da retirada do TCLE, a qualquer momento você poderá deixar de participar do estudo, sem qualquer prejuízo ou dano à sua pessoa.

Você não terá nenhum gasto ou ganho financeiro por participar na pesquisa.

Se você leu, entendeu e concorda em participar da pesquisa, por favor, coloque a data, seu nome e assine este documento.

Um Comitê de Ética em Pesquisa (CEP) é composto por um grupo de pessoas que são responsáveis por supervisionarem pesquisas em seres humanos que são realizadas na instituição e tem a função de proteger e garantir os direitos, a segurança e o bem-estar de todos os participantes de pesquisa que se voluntariam a participar da mesma. O CEP do Hospital das Clínicas e da Faculdade de Medicina de Ribeirão Preto é localizado no subsolo do hospital e funciona de segunda a sexta-feira, das $8: 00$ às $17: 00$ hs, telefone de contato (16) 3602-2228. 
Data:

Nome (participante):

Assinatura:

Data:

Nome (pesquisador que obtém o TCLE):

Assinatura: 


\section{APÊNDICE B - CONVITE PARA PARTICIPAÇÃO:}

Ao colega Ortopedista e Traumatologista.

Me chamo Bruno Adona Ribeiro, sou médico residente de Ortopedia e Traumatologia Hospital das Clínicas da Faculdade de Medicina de Ribeirão Preto da Universidade de São Paulo (HC-FMRP-USP) e mestrando do programa de Mestrado Profissional em Medicina desta instituição.

Este é um convite para que você participe de uma pesquisa que tem o intuito de traçar o perfil do médico especialista em Ortopedia e Traumatologia formado pelo HC-FMRP-USP. Temos ainda a intenção de avaliar indiretamente a formação do médico residente e buscar, através das suas respostas, meios de otimizar este serviço de educação médica tão importante e reconhecido no país.

A pesquisa pode ser encontrada no link disponibilizado abaixo e será realizada inteiramente através deste questionário eletrônico. Caso tenha problemas com o link, me envie um e-mail que encaminharei o link novamente. Responder todas as questões não levará mais do que 10 minutos e é de extrema importância para o sucesso dos nossos objetivos.

Em qualquer etapa da pesquisa, você poderá contatar-me pelo telefone número +55-16-98262-1713 ou por e-mail baribeiro@fmrp.usp.br, para esclarecimento de eventuais dúvidas acerca de procedimentos, riscos, benefícios, etc.

Link para acesso ao questionário:

https://forms.gle/UedQz7TLwZzJv6JNA 


\section{APÊNDICE C - QUESTIONÁRIO}

1. Se você leu, entendeu e concorda em participar da pesquisa, por favor, assinale a opção correspondente: *

- Concordo em participar da pesquisa.

- Não concordo em participar da pesquisa.

IDENTIFICAÇÃO

2. Sexo

O Masculino

o Feminino

3. Data de Nascimento

Exemplo: 7 de janeiro de 2019<smiles>[3H]I=CI</smiles>

Dados de Moradia

4. Cidade e estado

Ex: Ribeirão Preto - SP

O Ribeirão Preto - SP

Outro:

Graduação em Medicina

5. Nome da Instituição

O Faculdade de Medicina de Ribeirão Preto da Universidade de São Paulo Outro: 
6. Qual instituição de formação? *

O HC-FMRP-USP

Outro:

7. Ano de conclusão *

Digitar o ano com quatro dígitos

Avaliação do sistema de ensino da residência médica

8. Quão satisfeito você ficou com a carga horária de aulas teóricas do programa de residência? *

Nada satisfeito $1 \quad 2 \quad 3 \quad 4 \quad 5$ Muito satisfeito

9. Quão satisfeito você ficou com as discussões de casos clínicos com preceptores? *

Nada satisfeito $1 \quad 2 \quad 3 \quad 4 \quad 5$ Muito satisfeito

10. Quão satisfeito você ficou com o treinamento cirúrgico e ensino técnico? *

$\begin{array}{lllll}\text { Nada satisfeito } 1 & 2 & 3 & 4 & 5 \text { Muito satisfeito }\end{array}$

11. Quão satisfeito você ficou com o número de atendimentos e variabilidade dos casos? *

Nada satisfeito $1 \quad 2 \quad 3 \quad 4 \quad 5$ Muito satisfeito

12. Quão satisfeito você ficou com a capacitação para atendimento (diagnóstico, tratamento e seguimento) de casos de nível secundário de atenção à saúde *

$\begin{array}{lllll}\text { Nada satisfeito } 1 & 2 & 3 & 4 & 5 \text { Muito satisfeito }\end{array}$

13. Quão satisfeito você ficou com a capacitação para atendimento (diagnóstico, tratamento e seguimento) de casos de nível terciário de atenção à saúde *

Nada satisfeito $1 \quad 2 \quad 3 \quad 4 \quad 5$ Muito satisfeito 
14. Quão preparado para o mercado de trabalho você considera ter saído do Programa de Residência Médica? *

$\begin{array}{lllll}\text { Nada preparado } 1 & 2 & 3 & 4 & 5 \text { Muito preparado }\end{array}$

15. Com base nas respostas anteriores, o que mudaria se pudesse alterar o programa de residência médica do HC-FMRP-USP da sua época?

SITUAÇÃO APÓS A RESIDÊNCIA EM ORTOPEDIA E TRAUMATOLOGIA (R4 - R5)

16. Fez/faz algum tipo de especialização ou complementação especializada (R4 $\mathrm{R} 5)$ ? *

O Sim

○ Não Pular para a pergunta 28

17. Qual especialização você fez/faz? *

Marque todas que se aplicam.

o Coluna

O Joelho

○ Cirurgia da mão

- Ombro e Cotovelo

- Ortopedia oncológica

o Pé e Tornozelo

○ Quadril

- Traumatologia do esporte

- Reconstrução e Alongamento ósseo Ortopedia pediátrica e pé

- Trauma ortopédico

- Joelho e Trauma

- Ortopedia pediátrica 
18. Nome da instituição *
O HC-FMRP-USP
O UNIFESP
O IOT-USP
o Outro:

19. Tipo da instituição *
- Pública
o Privada
o Outro:

20. Foi/será concluída em que ano? *

21. Se já for concluída, qual porcentagem da sua carga horária semanal é diretamente dependente desta especialização?

$\begin{array}{lllllllllllll}0 \% & 0 & 1 & 2 & 3 & 4 & 5 & 6 & 7 & 8 & 9 & 10 & 100 \%\end{array}$

22. Fez/faz mais de um tipo de especialização ou complementação especializada (R4 - R5)? *

Duas ou mais especializações?
O Sim
O Não Pular para a pergunta 28

23. Qual segunda especialização você fez/faz? *

Marque todas que se aplicam.
O Coluna
O Joelho
○ Cirurgia da mão
- Ombro e Cotovelo
- Ortopedia oncológica
- Pé e Tornozelo
○ Quadril
- Traumatologia do esporte
- Reconstrução e Alongamento ósseo Ortopedia pediátrica e pé
o Trauma ortopédico 
O Joelho e Trauma

- Ortopedia pediátrica

24. Nome da instituição *

25. Tipo da instituição *

- Pública

O Privada

o Outro:

26. Foi/será concluída em que ano? *

27. Se já for concluída, qual porcentagem da sua carga horária semanal é diretamente dependente desta especialização?

$\begin{array}{lllllllllllll}0 \% & 0 & 1 & 2 & 3 & 4 & 5 & 6 & 7 & 8 & 9 & 10 & 100 \%\end{array}$

SITUAÇÃO APÓS A RESIDÊNCIA EM ORTOPEDIA E TRAUMATOLOGIA (PÓS GRADUAÇÃO)

28. Cursa ou cursou algum programa de Mestrado, Doutorado ou PósDoutorado? *

O $\operatorname{Sim}$

- Não Pular para a pergunta 44

SITUAÇÃO APÓS A RESIDÊNCIA EM ORTOPEDIA E TRAUMATOLOGIA (MESTRADO)

29. Cursa ou cursou Mestrado? *

O Sim

- Não Pular para a pergunta 34 
30. Nome da instituição *
O FMRP-USP
O IOT-USP
- UNIFESP
O Outro:

31. Tipo *

O Pública

- Privada

32. Concluído? *
o Sim
○ Não

33. Foi/será concluído em que ano? *

SITUAÇÃO APÓS A RESIDÊNCIA EM ORTOPEDIA E TRAUMATOLOGIA (DOUTORADO)

34. Cursa ou cursou Doutorado? *
o Sim
- Não Pular para a pergunta 39

35. Nome da instituição *
O HC-FMRP-USP
O IOT-USP
O UNIFESP
O Outro:

36. Tipo *

- Pública

- Privada 
37. Concluído? *
o Sim
O Não

38. Foi/será concluído em que ano? *

SITUAÇÃO APÓS A RESIDÊNCIA EM ORTOPEDIA E TRAUMATOLOGIA (PÓS-DOUTORADO)

39. Cursa ou cursou Pós-Doutorado? *

- Sim

- Não Pular para a pergunta 44

40. Nome da instituição *

41. Tipo *
- Pública
o Privada

42. Concluído? *

o Sim

○ Não

43. Foi/será concluído em que ano? * 
44. Possui algum título de especialista (Ex: TEOT)? *

o Sim

○ Não Pular para a pergunta 52

45. Especialidade obtida no primeiro título de especialista * Marque todas que se aplicam.

- Ortopedista e Traumatologista

o Outro:

46. Entidade que o concedeu *

Marque todas que se aplicam.

- SBOT

- Outro:

47. Especialidade obtida no segundo título de especialista

48. Entidade que o concedeu

49. Especialidade obtida no terceiro título de especialista

50. Entidade que o concedeu

51. Possui mais do que 3 títulos de especialista?

Se sim, digite na opção "Outros" quais são eles

o Sim

○ Não

o Outro: 
SITUAÇÃO APÓS A RESIDÊNCIA EM ORTOPEDIA E TRAUMATOLOGIA (CURSOS / COMPLEMENTAÇÃO)

52. Possui algum curso ou fez algum tipo de complementação especializada que considera importante à sua formação e carreira e que ainda não consta em suas respostas anteriores? *

o $\operatorname{Sim}$

○ Não Pular para a pergunta 57

53. Qual foi o curso ou complementação? *

54. Qual a duração em meses? *

55. Concedido por qual instituição? *

56. Em que cidade foi realizado? *

SITUAÇÃO APÓS A RESIDÊNCIA EM ORTOPEDIA E TRAUMATOLOGIA (ESPECIALIDADE MÉDICA)

57. Possui título de especialista em outra(s) especialidade(s) médica(s)? Se sim, qual(is)? *

\section{ATUAÇÃO PROFISSIONAL}

58. Qual sua principal área de atuação profissional atualmente? * 
Considerar a atividade que mais consome seu tempo, inclusive plantões. Você pode selecionar mais de uma opção.

- Em formação (residência/ complementação especializada)

- Ortopedia Geral

- Traumatologia (urgência e seguimento)

O Ortopedia especialidade

O Ensino / Pesquisa

- Gerenciamento de clínicas / hospitais na área médica

- Aposentado

- Outra atividade fora da medicina (especificar abaixo)

- Outra especialidade médica (especificar abaixo)

o Outro:

\section{ATUAÇÃO NO SUS}

59. Trabalha em hospitais ou serviços financiados pelo SUS? *

o Sim

○ Não Pular para a pergunta 63

60. Em quais cidade(s) e estado(s)? ${ }^{*}$

Ex: Ribeirão Preto - SP

0 Ribeirão Preto - SP

O São Paulo - SP

o Outro:

61. Total de horas semanais em hospitais ou serviços financiados pelo SUS? *

62. Há quanto tempo trabalha nestes hospitais ou serviços financiados pelo SUS? Em anos.

ATUAÇÃO EM HOSPITAIS PRIVADOS OU CONSULTÓRIO PRIVADO

63. Atua no sistema privado de Saúde? * 
O Sim

○ Não Pular para a pergunta 68

64. Em quais cidade(s) e estado(s)? *

O Ribeirão Preto - SP

O São Paulo - SP

o Outro:

65. Total de horas semanais em hospitais privados ou consultório privado? * Em horas

66. Há quanto tempo trabalha no sistema privado de Saúde? * Em anos.

67. Você é associado a algum convênio médico? *

O Sim

○ Não

\section{ATUAÇÃO FORA DA ÁREA DA SAÚDE}

68. Você possui alguma outra fonte de renda que não depende de sua formação como médico ortopedista? *

O Sim

O Não Pular para a pergunta 72

69. Qual a origem da fonte de renda fora da Ortopedia? *

- Fonte de renda familiar prévia

O Negócio adquirido após formação como ortopedista

o Outro:

70. Que tipo de atividades remuneradas são executadas por você e que não dependem da sua formação como ortopedista? * 
- Clínicas / hospitais

- Empresa na área de alimentação

o Empresa na área de transportes

- Empresa na área de moradia

- Empresa na área de vestuário

- Empresa de fabricação de produtos médicos

- Produção agropecuária

- Aluguel e venda de imóveis

- Palestrante / representante de indústria farmacêutica ou implantes

o Outro:

71. Quanto tempo da sua semana disponibiliza para este tipo de atividade? * Em horas.

\section{ÁREA DE ATUAÇÃO EM PESQUISA}

72. Você realiza pesquisa na área da saúde? *

o Sim

- Não Pular para a pergunta 74

73. Em que contexto desenvolve atividade de pesquisa? *

- Empresa privada

- Universidades públicas

o Universidades privadas

o Outro:

SITUAÇÃO APÓS A RESIDÊNCIA EM ORTOPEDIA E TRAUMATOLOGIA (FORMAÇÃO MÉDICA)

74. Você trabalha ou já trabalhou com o ensino médico (preceptoria / docência / livre docência) para a graduação ou programa de residência médica? *

O Sim

○ Não Pular para a pergunta 91 


\section{FORMAÇÃO MÉDICA - GRADUAÇÃO}

Docência e livre docência será avaliada em outra seção

75. Você trabalha ou já trabalhou com o ensino médico em nível de GRADUAÇÃO EM MEDICINA? *

O Sim

- Não Pular para a pergunta 79

76. Qual o tipo da instituição? *

O Pública

o Privada

77. Existe vínculo com a universidade/faculdade? *

O Sim

○ Não

78. Se trabalha ou já trabalhou, por quantos anos? *

SITUAÇÃO APÓS A RESIDÊNCIA EM ORTOPEDIA E TRAUMATOLOGIA FORMAÇÃO MÉDICA - RESIDÊNCIA MÉDICA

Docência e livre docência será avaliada em outra seção

79. Você trabalha ou já trabalhou com a formação médica durante a RESIDÊNCIA MÉDICA (preceptoria)? *

O $\operatorname{Sim}$

○ Não Pular para a pergunta 83

80. Qual o tipo da instituição? *

- Pública

- Privada

81. Existe vínculo com instituição de ensino? * 
o Sim

○ Não

82. Se trabalha ou já trabalhou, por quantos anos? *

\section{ÁREA DE ATUAÇÃO EM DOCÊNCIA}

83. Desenvolve atividades ligadas à Docência em Saúde? *

o Sim

○ Não Pular para a pergunta 91

\section{ÁREA DE ATUAÇÃO EM DOCÊNCIA \\ GRADUAÇÃO EM MEDICINA}

84. Exerce atividades de docência relacionadas à GRADUAÇÃO EM MEDICINA? *

O Sim

○ Não Pular para a pergunta 87

85. Qual o tipo de instituição? *

- Pública

- Privada

86. Há quanto tempo desenvolve esse tipo de atividade? * Em anos.

\section{ÁREA DE ATUAÇÃO EM DOCÊNCIA}

\section{RESIDÊNCIA MÉDICA}

87. Exerce atividades de docência relacionadas à RESIDÊNCIA MÉDICA? *

o $\operatorname{Sim}$ 
○ Não Pular para a pergunta 91

88. Presta este tipo de serviço em qual instituição de saúde? *

89. Quais atividades desenvolve para a residência médica? *

90. Há quanto tempo desenvolve esse tipo de atividade? *

Em anos.

\section{REMUNERAÇÃO}

91. Renda mensal aproximada (renda mensal por seu trabalho na área da saúde)? *

Em reais.

$0 \quad 0$ - 10 mil reais

- $10-20$ mil reais

○ 20 - 30 mil reais

o 30 - 40 mil reais

- 40 - 50 mil reais

o $50-60$ mil reais

o 60 - 70 mil reais

○ Mais de 70 mil reais

92. Você acha que seu salário é compatível com a sua profissão e a sua formação? *
O $\operatorname{Sim}$
○ Não
O Outro:

93. Quão satisfeito você está com sua remuneração mensal como médico ortopedista? *

Nada satisfeito $1 \quad 2 \quad 3 \quad 4 \quad 5$ Muito satisfeito 
94. Qual porcentagem da sua remuneração mensal advém de trabalho financiado pelo SUS? *

$\begin{array}{lllllllllllll}0 \% & 0 & 1 & 2 & 3 & 4 & 5 & 6 & 7 & 8 & 9 & 10 & 100 \%\end{array}$

95. Qual porcentagem da sua remuneração mensal advém de trabalho em hospitais ou consultórios particulares? *

$\begin{array}{lllllllllllll}0 \% & 0 & 1 & 2 & 3 & 4 & 5 & 6 & 7 & 8 & 9 & 10 & 100 \%\end{array}$

96. Qual porcentagem da sua remuneração mensal advém de trabalho com convênios médicos? *

$\begin{array}{lllllllllllll}0 \% & 0 & 1 & 2 & 3 & 4 & 5 & 6 & 7 & 8 & 9 & 10 & 100 \%\end{array}$

97. Qual porcentagem da sua remuneração mensal advém de trabalho ligado a formação médica (preceptoria/docência)? *

$\begin{array}{lllllllllllll}0 \% & 0 & 1 & 2 & 3 & 4 & 5 & 6 & 7 & 8 & 9 & 10 & 100 \%\end{array}$

98. Qual a porcentagem da sua remuneração mensal advém de atividade não relacionada a ortopedia? *

$\begin{array}{lllllllllllll}0 \% & 0 & 1 & 2 & 3 & 4 & 5 & 6 & 7 & 8 & 9 & 10 & 100 \%\end{array}$

ATIVIDADES EM ORTOPEDIA E TRAUMATOLOGIA

\section{VISÃO GERAL}

99. Qual o grau de satisfação com suas atividades em Ortopedia e Traumatologia hoje? *

Nada satisfeito $1 \quad 2 \quad 3 \quad 4 \quad 5$ Muito satisfeito

100. Justifique seu grau de satisfação de maneira sucinta 
101. Se estivesse terminando o sexto ano de medicina hoje, qual especialidade médica escolheria para sua carreira?

102. Se estivesse terminando o terceiro ano de residência médica em Ortopedia e Traumatologia hoje, qual especialização (R4-R5) você faria?

103. Deixe seu comentário (não obrigatório) sobre qualquer aspecto da sua formação, da sua carreira ou sobre esta pesquisa. Obrigado.

104. Se puder, ajude a pesquisa a atingir o maior número de pessoas possível. Forneça o contato de egressos ou compartilhe o e-mail recebido ou o link que consta no corpo do e-mail com os egressos conhecidos. E ainda, caso queira se identificar (não obrigatório) poderemos retirar seu e-mail/contato das próximas mensagens em busca da resposta dos demais egressos. Obrigado. 